\title{
Fluorinated Conformationally-Restricted y-Aminobutyric Acid Aminotransferase Inhibitors
}

\author{
Hejun Lu and Richard B. Silverman ${ }^{*}$ \\ Department of Chemistry, Department of Biochemistry, Molecular Biology, and Cell Biology, and \\ the Center for Drug Discovery and Chemical Biology, Northwestern University, Evanston, IL \\ 60208-3113, USA
}

\section{Abstract}

Based on the structures of several potent inhibitor molecules for $\gamma$-aminobutryric acid aminotransferase (GABA-AT) that were previously reported, six modified fluorine-containing conformationally-restricted analogues were designed, synthesized, and tested as GABA-AT inhibitors. The syntheses of all six molecules followed from a readily synthesized ketone intermediate. Three of the molecules were found to be irreversible inhibitors of GABA-AT with comparable or larger $k_{\text {inact }} / K_{\mathrm{I}}$ values than that of vigabatrin, a clinically used antiepilepsy drug, and the other three were reversible inhibitors. A possible mechanism for inactivation by one of the inactivators is proposed.

There are two principal neurotransmitters involved in the regulation of brain neuronal activity: $\gamma$-aminobutyric acid (GABA), one of the most widely distributed inhibitory neurotransmitters, and $L$-glutamic acid, an excitatory neurotransmitter. ${ }^{1}$ The GABA concentration is regulated by two pyridoxal 5'-phosphate (PLP)-dependent enzymes, $L$-glutamic acid decarboxylase (GAD), which catalyzes the conversion of $L$-glutamate to GABA, and GABA aminotransferase (GABA-AT), which degrades GABA to succinic semialdehyde (SSA) concomitant with the conversion of $\alpha$-ketoglutarate to $L$-glutamate. ${ }^{2}$ When the concentration of GABA diminishes below a threshold level in the brain, convulsions result; ${ }^{3}$ raising the brain GABA levels terminates the seizure. ${ }^{4} \mathrm{~A}$ reduction in the concentrations of GABA and of the enzyme GAD has been implicated not only in the symptoms associated with epilepsy 5,6 but also with several other neurological diseases such as Huntington's chorea, ${ }^{7,8}$ Parkinson's disease, 9,10 Alzheimer's disease, ${ }^{11}$ and tardive dyskinesia. ${ }^{12}$ GABA brain levels cannot be increased by administration of GABA because it does not cross the blood-brain barrier. An approach that has been successful to increase brain GABA levels is the use of a compound that crosses the blood-brain barrier and then inhibits or inactivates GABA-AT, thereby increasing the GABA concentration. Numerous competitive inhibitors of GABA-AT, particularly compounds having a similar backbone structure to GABA, 13 show anticonvulsant activity. A variety of mechanismbased inactivators ${ }^{14}$ of GABA-AT ${ }^{15}$ also have been shown to be effective anticonvulsant agents. The most effective of the mechanism-based inactivators as an anticonvulsant agent is 4 -amino-5-hexenoic acid (1, Figure $1 ; \gamma$-vinyl GABA), ${ }^{16}$ which has the commercial generic name vigabatrin. This compound, which has high potency, ${ }^{17}$ has been shown to be an effective treatment for epilepsies that are resistant to other anticonvulsant drugs 18 and currently is prescribed in over 60 countries worldwide, but it was not approved

*Address correspondence to this author at the Department of Chemistry.

Supporting Information

Supporting Information Available: Combustion analyses. This material is available free of charge via the Internet at http://pubs.acs.org. 
in the U. S. It also was found that vigabatrin prevents cocaine addiction in rats and baboons. 19 This activity was observed with other forms of addiction, including nicotine addiction 20 and methamphetamine, alcohol, and heroin addictions. ${ }^{21}$ Self-administration of cocaine by rats decreased or was prevented by vigabatrin administration in a dose-dependent fashion, without affecting the craving for food. ${ }^{22} \mathrm{GABA}$ was found to antagonize the extracellular dopamine levels responsible for drug addiction, and by positron emission tomography (PET) in primates, it was shown that vigabatrin, which causes a rise in GABA levels, inhibits these drug-induced dopamine increases. ${ }^{21}$ However, because vigabatrin is not approved in the U. S., new GABA-AT inhibitors and inactivators are needed.

Conformationally restricted analogues of GABA are of considerable interest among medicinal chemists. ${ }^{23} \mathrm{We}$ previously reported the design and synthesis of a series of conformationally restricted analogues of GABA. Among them, $(1 R, 4 S)$-4-aminocyclopent-2-enecarboxylic acid (2) was shown to be a potent inhibitor and substrate of GABA-AT, but it was not a timedependent inactivator. ${ }^{24}(1 S, 3 S)$-3-Amino-4-methylenecyclopentane carboxylic acid (3) was found to inactivate GABA-AT, but only in the absence of 2-mercaptoethanol (indicating that a reactive species was produced that was released from the enzyme prior to inactivation), while $(1 S, 3 S)$-3-amino-4-difluoromethylenecyclopentanecarboxylic acid (4) is a much more potent time-dependent inhibitor of $\gamma$-aminobutyric acid aminotransferase, even in the presence of 2 mercaptoethanol (indicating that any reactive species generated are not released prior to inactivation). ${ }^{25}$ Compound $\mathbf{4}$ is 187 times more potent of an inactivator of GABA-AT than vigabatrin, and the corresponding $E$ - and Z-monofluoro analogues of $\mathbf{3}$ also inactivate GABAAT, but not with the same potency as 4 . This suggests an important significance for fluorine in the molecules.

Fluorine and fluoroalkyl substitutents have an important electronic effect on the neighboring groups in a molecule and also mimic hydrogen and alkyl groups, respectively. ${ }^{26}$ Therefore, the introduction of one or more fluorine-containing groups into molecules alters their physical properties, as well as their biological activities. ${ }^{27}$ Fluorinated substrates also can be used as mechanistic probes and inhibitors for obtaining information about the catalytic mechanism of various enzymatic transformations. ${ }^{28}$ Consequently, it was thought that other fluorinated conformationally-restricted analogues of $\mathbf{2}$ and $\mathbf{3}$ should be evaluated for their inhibitory activities. Based on that hypothesis, we designed six new fluorine-containing conformationally-restricted vigabatrin analogues (5-10, Figure 2). Compounds 5, 6 and $\mathbf{7}$ are C-3 fluorine or fluoroalkyl substituted analogues of $\mathbf{2}$, while $\mathbf{8 , 9}$ and $\mathbf{1 0}$ are trifluoromethylated analogues of $\mathbf{3}$ and $\mathbf{4}$. The presence of strongly electron-withdrawing fluorine and fluoroalkyl groups also may enhance binding and/or reactivity of these compounds during GABA-AT turnover based on a Michael addition mechanism. ${ }^{23 a}$ The results of this investigation are reported here.

\section{Results and Discussion}

\section{Chemistry}

Key intermediate $\mathbf{1 6}$ for the synthesis of all of the analogues was synthesized according to a modification of a procedure we reported previously ${ }^{29}$ (Scheme 1). Protection of $\mathbf{1 1}$ was realized by treatment with $p$-methoxybenzyl chloride $(\mathrm{PMBCl})$ in the presence of sodium hydride in DMF instead of LiHMDS in THF as reported. This revised procedure turned out to be much easier and gave higher yields of product.

The synthesis of $\mathbf{5}$ was first attempted by a direct halogen exchange reaction of $\mathbf{1 7}$. However, treatment of $\mathbf{1 7}$ with $\left(\mathrm{PhSO}_{2}\right)_{2} \mathrm{NF} / \mathrm{nBuLi}$ resulted in the ent-12 reduction product as the major product. Conversion of $\mathbf{1 7}$ to organotin intermediate 18, followed by fluorine-metal exchange 
with $\mathrm{XeF}_{2}$ afforded 19 in a satisfactory yield (Scheme 2). Deprotection of 19 with ceric ammonium nitrate (CAN) followed by acidic hydrolysis gave $\mathbf{5}$.

Syntheses of target molecules $\mathbf{6}$ and 7 via elimination of an alcohol or the corresponding tosylated derivative were unsuccessful (Scheme 3). Treatment of $\mathbf{1 6}$ with TMSRf ( $\mathrm{Rf}=\mathrm{CF}_{3}$ or $\mathrm{CF}_{3} \mathrm{CF}_{2}$ ) in the presence of a catalytic amount of TBAF afforded tertiary alcohols 21a and $\mathbf{2 1 b}$ in excellent yields. ${ }^{30}$ However, direct dehydration of $\mathbf{2 1 a}$ or $\mathbf{2 1 \mathbf { b }}$ with various dehydration conditions failed to produce the desired products $22 \mathbf{a}$ and $22 \mathbf{b}$. Activation of $21 \mathbf{a}$ and $21 \mathbf{b}$ with $\mathrm{TsCl}$ in the presence of $\mathrm{NaH}$ successfully gave the tosylates $\mathbf{2 3} \mathbf{a}$ and $\mathbf{2 3 \mathbf { b }}$, respectively. Unfortunately, attempted elimination reactions of 23a and 23b with various bases always resulted in formation of $\mathbf{2 1 a}$ and $\mathbf{2 1 b}$, respectively, with only a trace amount of the desired products detected.

An alternative synthesis of target molecule $\mathbf{6}$ (Scheme 4) started with iodination of $\mathbf{1 6}$ with hydrazine and iodine followed by elimination of one molecule of $\mathrm{HI}$ in the presence of potassium tert-butoxide to give 17. Direct trifluoromethylation of $\mathbf{1 7}$ with in situ generated $\mathrm{CF}_{3} \mathrm{Cu}$ from $\mathrm{FSO}_{2} \mathrm{CF}_{2} \mathrm{CO}_{2} \mathrm{Me}$ (methyl fluorosulfonyldifluoroacetate; MFSDA) and $\mathrm{CuI}^{31}$ successfully afforded 22a. Removal of the PMB group with CAN followed by acidic hydrolysis gave 6.

Compound 7 was synthesized from $\mathbf{1 7}$ using steps similar to those used to prepare $\mathbf{6}$ (Scheme 5). A first attempt at pentafluoroethylation of 17 with $\mathrm{CF}_{3} \mathrm{CF}_{2} \mathrm{CO}_{2} \mathrm{Na} / \mathrm{CuI}$ at $140{ }^{\circ} \mathrm{C}$ only resulted in decomposition of the substrate. Treatment of 17 with $\mathrm{CF}_{3} \mathrm{CF}_{2} \mathrm{SiMe}_{3} / \mathrm{KF} / \mathrm{CuI}$, however, afforded 22b in good yields.

A Wittig reaction of 16 with $\mathrm{CHBr}=\mathrm{PPh}_{3}$, generated in situ from bromomethyltriphenylphosphonium bromide and tert-BuOK afforded an $E / Z$ mixture of bromomethylenes $\mathbf{2 5 a}$ and $\mathbf{2 5 b}$, which was easily separated by column chromatography on silica gel. The conformations of the double bonds in the two isomers were determined based on NOE experiments. Trifluoromethylation of $\mathbf{2 5 a}$ and $\mathbf{2 5} \mathbf{b}$ with $\mathrm{CF}_{3} \mathrm{Cu}$ under similar conditions used for $\mathbf{1 7}$ produced compounds $\mathbf{2 6 a}$ and $\mathbf{2 6 \mathbf { b }}$, respectively. Removal of the PMB protecting group with CAN followed by acidic hydrolysis gave $\mathbf{8}$ and $\mathbf{9}$ (Scheme 6).

Treatment of 16 with $\mathrm{CBr}_{4}$ and $\mathrm{PPh}_{3}$ in toluene afforded 28, which was double trifluoromethylated with in situ generated $\mathrm{CF}_{3} \mathrm{Cu}$ to give 29. Removal of the PMB group with CAN, followed by hydrolysis with $4 N \mathrm{HCl}$ (aq.) at $75^{\circ} \mathrm{C}$ gave $\mathbf{1 0}$ (Scheme 7).

It is noteworthy that, compared to the compounds with an exocyclic double bond (27a, 27b, and 30), the hydrolysis of 20, 24a, and $\mathbf{2 4 b}$, which have endocyclic double bonds, was found to be much easier. The reaction is usually completed in one hour when the compounds are treated with $4 \mathrm{~N}$ aq. $\mathrm{HCl}$ at $70{ }^{\circ} \mathrm{C}$. Prolonged heating and stirring of these compounds under these conditions resulted in major side reactions. No such side reactions were observed from hydrolysis of 27a, 27b, and $\mathbf{3 0}$.

\section{Enzyme inhibition results}

Compounds 6, 8, and $\mathbf{9}$ showed concentration and time-dependent inhibition of pig brain GABA-AT in the presence of $\beta$-mercaptoethanol (Table 1). Compounds $\mathbf{5 , 7}$, and $\mathbf{1 0}$ showed only weak reversible inhibition of GABA-AT in the presence of $\beta$-mercaptoethanol. None of the three reversible inhibitor target molecules was more potent than $\mathbf{2}$ or $\mathbf{4}$. However, the irreversible inhibitors were comparable to vigabatrin as inactivators of GABA-AT. It is interesting that although 6 was designed to be a reversible inhibitor of GABA-AT because a simple elimination of HF was not initially apparent, it was found to be an irreversible inhibitor. Compounds 5 and 7, which differ from 6 only by the length of the fluoroalkyl chain, are 
reversible inhibitors of GABA-AT. Although 8 and $\mathbf{9}$ are irreversible inhibitors of GABA-AT, as expected, introduction of a second trifluoromethyl group makes $\mathbf{1 0}$ a weak reversible inhibitor.

Exhaustive dialysis of GABA-AT that was inactivated by $\mathbf{6 , 8}, \mathbf{8}$, and $\mathbf{9}$ against potassium pyrophosphate buffer $(\mathrm{pH} 8.5)$ resulted in different extents of irreversibility of inhibition. Compared to the control, $48 \%$ and $13 \%$ of enzyme activity was recovered for $\mathbf{6}$ and $\mathbf{8}$, respectively, after $22 \mathrm{~h}$ of dialysis, while the percentage of recovered enzyme activity for 9 continued to increase with extended dialysis. These results suggest that at least part of the adducts formed between the enzyme and $\mathbf{6}$ and $\mathbf{8}$ are stable, while at least one with $\mathbf{9}$ can be slowly hydrolyzed upon dialysis. Incubation of $\mathbf{6 , 8}$ and $\mathbf{9}$ with GABA-AT in the presence of GABA resulted in a significant increase in their $t_{1 / 2}$ of inactivation (slower rate of inactivation), indicating active-site binding to GABA-AT by these compounds. ${ }^{32}$

A possible mechanism for inactivation of GABA-AT by 6 is shown in Scheme 8. Initial Schiff base formation with the PLP followed by tautomerization gives 31. Michael addition to this trifluoromethyl-activated Michael acceptor ${ }^{33}$ by Lys329 (X = Lys329) or hydroxide (X = $\mathrm{HO}^{-}$) results in 32, which can eliminate fluoride ion to give a highly reactive exocyclic difluoromethylene group ${ }^{32}$ conjugated to the PMP iminium (33). This should lead to rapid nucleophilic attack, ${ }^{32}$ either by the enzyme (pathway a) or by water (pathway b) to give $\mathbf{3 4}$ or 36, respectively. Fluoride ion elimination and hydrolysis would give 35 (inactivation) or 38 (turnover). Inactivation by $\mathbf{8}$ and $\mathbf{9}$ may be related to the mechanism of inactivation proposed for 4.25

To test this mechanism, fluoride ion release was monitored during inactivation. GABA-AT was incubated with all six compounds for two hours, and the fluoride ion concentration was monitored. With 6, 270 fluoride ions were released per enzyme dimer inactivated. This suggests that possibly 90 molecules of $\mathbf{6}$ are turned over for each inactivation event (partition ratio of 89). Possibly, the activated intermediate $\mathbf{3 3}$ undergoes reaction with water (pathway b) 89 times for each attack by an active site residue (pathway a). Depending on what enzyme residue reacts with 33, the carboxylic acid derivative product formed may or may not be stable to conditions of dialysis, leading to partial reactivation of the enzyme during dialysis. For 7, 109 fluoride ions were released, and for the other four compounds, less than 6 fluoride ions were released during inactivation.

Enzyme activity was monitored concomitantly with fluoride ion release during inactivation of GABA-AT by 6. A good correlation was observed (Figure 3), which suggests that inactivation occurs as a consequence of fluoride ion release. When GABA-AT was substituted by human albumin, no fluoride ion was released, indicating that the presence of a protein is not responsible for the fluoride ion release.

Figure 4 shows the time-dependent increase in fluoride ion concentration when GABA-AT was incubated with 7 , a weak reversible inhibitor. The fluoride ion concentration reached it highest level in 2-3 hours. No fluoride ion was released when 7 was incubated with albumin, indicating a GABA-AT-dependent reaction. This suggests that the corresponding reactive intermediate (related to $\mathbf{3 3}$ in Scheme 8) only undergoes hydrolysis (possibly because of steric hindrance by the trifluoromethyl group of 7 that replaces the fluoride in 6).

\section{Conclusion}

Two series of fluorinated compounds were designed as potential inhibitors and inactivators of GABA-AT based on the high potency of 4 . The $k_{\text {inact }} / K_{\mathrm{I}}$ value for $\mathbf{8}\left(0.37 \mathrm{mM}^{-1} \mathrm{~min}^{-1}\right)$ is greater than that for the epilepsy drug vigabatrin $\left(0.28 \mathrm{mM}^{-1} \mathrm{~min}^{-1}\right)$; that for $6(0.16$ $\left.\mathrm{mM}^{-1} \min ^{-1}\right)$ and $9\left(0.18 \mathrm{mM}^{-1} \mathrm{~min}^{-1}\right)$ are slightly lower. None of these, however, is as 
efficient an inactivator as $4\left(52 \mathrm{mM}^{-1} \mathrm{~min}^{-1}\right)$. Compounds 5-7 were designed as reversible inhibitors, so it was unexpected that $\mathbf{6}$ was a potent time-dependent inactivator. It appears that there is more to the effective binding of compounds to GABA-AT than just the fluorine atoms. Other structures that more closely resemble $\mathbf{4}$ are being constructed.

\section{Experimental}

\section{General Methods and Reagents}

Optical spectra and GABA-AT assays were recorded on a Perkin-Elmer Lambda $10 \mathrm{UV} / \mathrm{Vis}$ spectrophotometer. ${ }^{1} \mathrm{H}$ NMR spectra were recorded on a Varian Gemini $300 \mathrm{MHz}$ NMR spectrometer. Chemical shifts are reported as $\delta$ values in parts per million downfield from TMS as the internal standard in $\mathrm{CDCl}_{3}$. For samples run in $\mathrm{D}_{2} \mathrm{O}$, the $\mathrm{HOD}$ resonance was arbitrarily set at $4.60 \mathrm{ppm}$. $\mathrm{CClF}_{3}$ was selected as an external standard with $\delta 0.0 \mathrm{ppm}$ for ${ }^{19} \mathrm{~F} \mathrm{NMR}$. Melting points were determined on a Fisher-Johns melting point apparatus and are uncorrected. Combustion analyses were performed by Oneida Research Laboratories, NY. High resolution mass spectra and accurate mass spectra were obtained on a VG-70-250SE high-resolution spectrometer and a Micromass Quattro II LC/MS spectrometer. An Orion Research Model $702 \mathrm{~A} \mathrm{pH}$ meter with a general combination electrode was used for $\mathrm{pH}$ measurements. Fluoride ion concentration measurements were obtained using an Orion Research model 702A pH meter with an Orion Research model 96-09 combination fluoride electrode. Flash column chromatography was carried with Merck silica gel 60 (230-400 mesh ASTM). TLC was run with EM Science silica gel 60 F254 precoated glass plates.

All reagents were purchased from Aldrich Chemical Co. and were used without further purification except anhydrous ether and tetrahydrofuran (THF), which were distilled from sodium metal under nitrogen and anhydrous dichloromethane, which was distilled from calcium hydride.

(1S,4R)-6-lodo-2-(4-methoxybenzyl)-2-azabicyclo[2.2.1]hept-5-en-3-one (17)Compound $16(0.246 \mathrm{~g}, 1.0 \mathrm{mmol})^{29}$ was dissolved in anhydrous ethanol $(5 \mathrm{~mL})$ and was added via syringe to a solution of hydrazine hydrate $(51 \%$ of hydrazine, $1.02 \mathrm{~mL}, 21.0 \mathrm{mmol})$ and $\mathrm{Et}_{3} \mathrm{~N}(2.18 \mathrm{~mL}, 15.7 \mathrm{mmol})$ in anhydrous ethanol $(5 \mathrm{~mL})$ while stirring. The resulting colorless solution was heated to reflux and stirred under argon for $1 \mathrm{~h}$. The reaction mixture was then evaporated under vacuum to give the crude hydrazone product as a colorless oil, which was used directly in the next step without further purification. $\mathrm{I}_{2}(0.508 \mathrm{~g}, 2.0 \mathrm{mmol})$ was dissolved in anhydrous benzene $(6 \mathrm{~mL})$ and was added dropwise into a solution of the above hydrazone and $\mathrm{Et}_{3} \mathrm{~N}(1.1 \mathrm{~mL}, 8.0 \mathrm{mmol})$ in anhydrous benzene $(5 \mathrm{~mL})$ with stirring at room temperature. The resulting brown suspension was stirred at room temperature under argon for $1.5 \mathrm{~h}$. Water $(20 \mathrm{~mL})$ was added, and the resulting two layers were separated; the aqueous layer was further extracted with ether $(20 \mathrm{~mL} \times 3)$. The combined organic layers were washed with aqueous $\mathrm{HCl}(0.5 \mathrm{~N}, 10 \mathrm{~mL})$, water $(10 \mathrm{~mL})$, saturated aqueous $\mathrm{NaHCO}_{3}(20$ $\mathrm{mL})$, brine $(20 \mathrm{~mL} \times 2)$, and dried over $\mathrm{MgSO}_{4}$. The solvent was removed under vacuum, and the resulting crude product was purified via column chromatography on silica gel (hexanes/ EtOAc 9:1) to give the diiodo intermediate as a light brown oil, which was dissolved in anhydrous ether and treated by dropwise addition of two equiv of tert-BuOK at room temperature; the resulting brown suspension was stirred overnight. Water was added, and the two layers were separated. The aqueous layer was further extracted with ether, and the combined ether solutions were washed with brine and dried over anhydrous $\mathrm{MgSO}_{4}$. Ether was removed under vacuum, and the resulting crude product was purified via column chromatography on silica gel (hexanes/EtOAc 9:1) to give $\mathbf{1 7}$ as a light green oil (213 mg, $60 \%) .{ }^{1} \mathrm{H}$ NMR $\left(400 \mathrm{MHz}, \mathrm{CDCl}_{3}\right) \delta 7.19(2 \mathrm{H}, \mathrm{d}, J=8.5 \mathrm{~Hz}), 6.96(1 \mathrm{H}, \mathrm{s}), 6.89(2 \mathrm{H}, \mathrm{d}, J=$ $8.5 \mathrm{~Hz}), 4.53(1 \mathrm{H}, \mathrm{d}, J=14.5 \mathrm{~Hz}), 4.06(1 \mathrm{H}, \mathrm{s}), 4.01(1 \mathrm{H}, \mathrm{d}, J=14.5 \mathrm{~Hz}), 3.82(3 \mathrm{H}, \mathrm{s}), 3.36$ $(1 \mathrm{H}, \mathrm{s}), 2.31(1 \mathrm{H}, \mathrm{d}, J=7.5 \mathrm{~Hz}), 2.22(1 \mathrm{H}, \mathrm{d}, J=7.5 \mathrm{~Hz}) .{ }^{13} \mathrm{C}$ NMR $\left(100 \mathrm{MHz}, \mathrm{CDCl}_{3}\right) \delta$ 
$178.50,159.36,144.04,129.84,128.73,114.32,98.91,71.65,58.13,56.33,55.38,46.83 . \mathrm{m} /$ $z$ (ESI, MeOH): $378(\mathrm{M}+\mathrm{Na})^{+}$. HRMS calcd. For $\mathrm{C}_{14} \mathrm{H}_{14} \mathrm{O}_{2} \mathrm{NI}$ : 355.0064. Found 355.0057.

(1S,4R)-2-(4-Methoxybenzyl)-6-trimethylstannanyl-2-azabicyclo[2.2.1]hept-5en-3-one (18)—Compound 17 (41 mg, $0.115 \mathrm{mmol})$ was dissolved in anhydrous toluene (4 $\mathrm{mL})$ under argon, followed by addition of $\mathrm{Pd}\left(\mathrm{PPh}_{3}\right)_{4}(20 \mathrm{mg}, 0.017 \mathrm{mmol})$ and

$\mathrm{Me}_{3} \mathrm{SnSnMe}_{3}(45 \mathrm{mg}, 0.139 \mathrm{mmol}$ ). A light yellow solution formed, which was heated to reflux under argon and stirred for $1 \mathrm{~h}$. Toluene was evaporated under vacuum, and the residue was purified via column chromatography on silica gel (hexanes/EtOAc 3:1) to give $\mathbf{1 8}$ (25 mg, $56 \%)$ as a colorless oil. ${ }^{1} \mathrm{H}$ NMR $\left(500 \mathrm{MHz}, \mathrm{CDCl}_{3}\right) \delta 7.14(2 \mathrm{H}, \mathrm{d}, J=8.5 \mathrm{~Hz}), 6.88(2 \mathrm{H}, \mathrm{d}$, $J=8.5 \mathrm{~Hz}), 6.85(1 \mathrm{H}, \mathrm{m}), 4.67(1 \mathrm{H}, \mathrm{d}, J=15.0 \mathrm{~Hz}), 4.13(1 \mathrm{H}, \mathrm{s}), 3.81(3 \mathrm{H}, \mathrm{s}), 3.47(1 \mathrm{H}, \mathrm{s})$, $3.41(1 \mathrm{H}, \mathrm{d}, J=15.0 \mathrm{~Hz}), 2.24(1 \mathrm{H}, \mathrm{d}, J=7.5 \mathrm{~Hz}), 2.00(1 \mathrm{H}, \mathrm{d}, J=8.0 \mathrm{~Hz}), 0.16(9 \mathrm{H}, \mathrm{s}) .{ }^{13} \mathrm{C}$ $\mathrm{NMR}\left(\mathrm{CDCl}_{3}, 125.6 \mathrm{MHz}\right) \delta 179.83,159.03,153.07,148.19,129.26,129.12,114.12,66.20$, 58.27, 55.68, 55.34, 47.56, -9.28. $\mathrm{m} / z$ (EI, DCM): $389.0(\mathrm{M})^{+}, 374.0\left(\mathrm{M}-\mathrm{CH}_{3}\right)^{+}, 211.0(\mathrm{M}-$ PMB - CONH $\left.-\mathrm{CH}_{3}\right)^{+}, 121.0(\mathrm{PMB})^{+}$. HRMS calcd. for $\mathrm{C}_{17} \mathrm{H}_{23} \mathrm{O}_{2} \mathrm{~N}^{116} \mathrm{Sn}(\mathrm{M})^{+}: 389.0741$. Found 389.0749; calcd for $\mathrm{C}_{16} \mathrm{H}_{20} \mathrm{O}_{2} \mathrm{~N}^{116} \mathrm{Sn}\left(\mathrm{M}-\mathrm{CH}_{3}\right)^{+}$: 374.0506 . Found 374.0504.

(1S,4R)-6-Fluoro-2-(4-methoxybenzyl)-2-azabicyclo[2.2.1]hept-5-en-3-one (19) -AgOTf ( $48 \mathrm{mg}, 0.187 \mathrm{mmol}$ ) was dissolved in dry DCM under argon. Compound 18 (73.4 $\mathrm{mg}, 0.187 \mathrm{mmol}$ ) and 2,6-di-tert-butyl-4-methylpyridine (19 mg, $0.094 \mathrm{mmol})$ in dry DCM (1 $\mathrm{mL}$ ) was added via syringe, followed by immediate addition of $\mathrm{XeF}_{2}(38 \mathrm{mg}, 0.225 \mathrm{mmol})$ in DCM. The resulting reaction mixture was shielded from light and stirred at room temperature for $15 \mathrm{~min}$. The reaction mixture was then partitioned between saturated aq. $\mathrm{NaHCO}_{3}$ and $\mathrm{CHCl}_{3}$, and the aqueous layer was further extracted with $\mathrm{CHCl}_{3}(20 \mathrm{~mL})$. The combined $\mathrm{CHCl}_{3}$ solutions were washed with brine $(20 \mathrm{~mL})$ and dried over anhydrous $\mathrm{MgSO}_{4}$. The $\mathrm{CHCl}_{3}$ was removed under vacuum, and the residue was purified via column chromatography on silica gel (hexanes/EtOAc 3:1) to give $19(20 \mathrm{mg}, 30 \%)$ as a light yellow oil. ${ }^{1} \mathrm{H}$ NMR $\left(400 \mathrm{MHz}, \mathrm{CDCl}_{3}\right) \delta 7.15(2 \mathrm{H}, \mathrm{d}, J=8.8 \mathrm{~Hz}), 6.86(2 \mathrm{H}, \mathrm{d}, J=8.4 \mathrm{~Hz}), 5.57(1 \mathrm{H}, \mathrm{s}), 4.48(1 \mathrm{H}$, $\mathrm{d}, J=14.8 \mathrm{~Hz}), 4.08(1 \mathrm{H}, \mathrm{d}, J=14.8 \mathrm{~Hz}), 3.89(1 \mathrm{H}, \mathrm{s}), 3.80(1 \mathrm{H}, \mathrm{s}), 3.24(1 \mathrm{H}, \mathrm{s}), 2.33-2.38$ $(2 \mathrm{H}, \mathrm{m}) .{ }^{19} \mathrm{~F}$ NMR $\left(376 \mathrm{MHz}, \mathrm{CDCl}_{3}\right) \delta-119.72(1 \mathrm{~F}, \mathrm{~s}) .{ }^{13} \mathrm{C} \mathrm{NMR}\left(\mathrm{CDCl}_{3}, 100.63 \mathrm{MHz}\right) \delta$ 177.01, 173.97, 159.20, 129.68, 128.27, 114.11, 105.37 (d, $J=7.3 \mathrm{~Hz}), 62.64,57.16,55.33$, 49.62, 47.12. $\mathrm{m} / z$ (EI, DCM): $247.1(\mathrm{M})^{+}, 163.1,121.1(\mathrm{PMB})^{+}$. HRMS calcd. for $\mathrm{C}_{14} \mathrm{H}_{14} \mathrm{O}_{2} \mathrm{NF}(\mathrm{M})^{+}:$247.1003. Found 247.1003.

(1S,4R)-6-Fluoro-2-azabicyclo[2.2.1]hept-5-en-3-one (20)—This compound was synthesized from 19 using general procedure II (see below) in a 55\% yield. ${ }^{1} \mathrm{H}$ NMR (400.168 $\left.\mathrm{MHz}, \mathrm{CDCl}_{3}\right) \delta 6.41(1 \mathrm{H}, \mathrm{s}), 5.59(1 \mathrm{H}, \mathrm{s}), 4.12(1 \mathrm{H}, \mathrm{s}), 3.10(1 \mathrm{H}, \mathrm{s}), 2.44(2 \mathrm{H}, \mathrm{s}) .{ }^{19}{ }^{\prime} \mathrm{F}$ NMR $\left(376.492 \mathrm{MHz}, \mathrm{CDCl}_{3}\right) \delta-120.59(1 \mathrm{~F}, \mathrm{~s}) .{ }^{13} \mathrm{C} \mathrm{NMR}\left(\mathrm{CDCl}_{3}, 125.614 \mathrm{MHz}\right) \delta 184.95,175.63$ $\left(\mathrm{d}, J_{F C}=304.9 \mathrm{~Hz}\right), 105.88,59.52,58.49,49.45 . \mathrm{m} / \mathrm{z}(\mathrm{CI}, \mathrm{DCM}): 128.1(\mathrm{M}+1)^{+}, 85.3(\mathrm{M}-$ $\mathrm{CON})^{+}$. HRMS calcd. For $\mathrm{C}_{6} \mathrm{H}_{7} \mathrm{ONF}$ : 128.0506. Found 128.0511 .

(1R,4S)-4-Amino-3-fluoro-cyclopent-2-ene carboxylic acid (5)-This compound was synthesized from $\mathbf{2 0}$ using general procedure III in a yield of $64 \%$ as a light yellow solid, mp 201.0-202.5 ${ }^{\circ} \mathrm{C}^{;}{ }^{1} \mathrm{H}$ NMR $\left(\mathrm{D}_{2} \mathrm{O}, 499.511 \mathrm{MHz}\right) \delta 5.68(1 \mathrm{H}, \mathrm{s}), 4.45(1 \mathrm{H}, \mathrm{d}, J=2.9 \mathrm{~Hz})$, $3.66(1 \mathrm{H}, \mathrm{d}, J=4.0 \mathrm{~Hz}), 2.83(1 \mathrm{H}, \mathrm{dt}, J=14.5 \mathrm{~Hz}, 9.0 \mathrm{~Hz}), 2.20(1 \mathrm{H}, \mathrm{dt}, J=14.5 \mathrm{~Hz}, 4.5$ Hz). ${ }^{19} \mathrm{~F}$ NMR $\left(\mathrm{D}_{2} \mathrm{O}, 376.493 \mathrm{MHz}\right) \delta-128.97(1 \mathrm{~F}, \mathrm{~d}, J=4.5 \mathrm{~Hz}) .{ }^{13} \mathrm{C}$ NMR $\left(\mathrm{D}_{2} \mathrm{O}, 125.614\right.$ $\mathrm{MHz}) \delta 177.18,157.61\left(\mathrm{~d}, J_{F C}=280.2 \mathrm{~Hz}\right), 109.21\left(\mathrm{~d}, J_{F C}=12.1 \mathrm{~Hz}\right), 51.37\left(\mathrm{~d}, J_{F C}=22.2\right.$ $\mathrm{Hz}), 42.57\left(\mathrm{~d}, J_{F C}=8.2 \mathrm{~Hz}\right), 29.32\left(\mathrm{~d}, J_{F C}=4.0 \mathrm{~Hz}\right) . \mathrm{m} / \mathrm{z}(\mathrm{EI}, \mathrm{MeOH}): 145.1(\mathrm{M})^{+}, 126.1$, $100.1\left(\mathrm{M}-\mathrm{CO}_{2} \mathrm{H}\right)^{+}$. HRMS calcd. For $\mathrm{C}_{6} \mathrm{H}_{8} \mathrm{O}_{\mathrm{FC}} \mathrm{NF}$ : 145.0534. Found 145.0530. Anal. $\left(\mathrm{C}_{6} \mathrm{H}_{8} \mathrm{O}_{2} \mathrm{NF} .0 .5 \mathrm{H}_{2} \mathrm{O}\right) \mathrm{C}, \mathrm{H}, \mathrm{N}$. 
(1S,4S,6SR)-6-Hydroxy-6-trifluoromethyl-2-(4'-methoxybenzyl)-azabicyclo [2.2.1] heptan-3-one (21a)-To a solution of $\mathbf{1 6}(0.123 \mathrm{~g}, 0.5 \mathrm{mmol})$ in dry THF $(4 \mathrm{~mL})$ was added $\mathrm{TMSCF}_{3}(0.107 \mathrm{mg}, 0.75 \mathrm{mmol})$. Tetrabutylammonium fluoride (TBAF) (1.0 M solution in THF, $50 \mu \mathrm{L}, 0.05 \mathrm{mmol}$ ) was added dropwise. The resulting mixture was stirred under nitrogen for $2 \mathrm{~h}$ and was concentrated under vacuum. The residue was purified by column chromatography (hexanes: EtOAc 2:1 to 1:1), giving 21a $(0.149 \mathrm{~g}, 94 \%)$ as a white solid. ${ }^{1} \mathrm{H}$ $\operatorname{NMR}\left(400 \mathrm{MHz}, \mathrm{CDCl}_{3}\right) \delta 7.19(2 \mathrm{H}, \mathrm{d}, J=8.4 \mathrm{~Hz}), 6.87(2 \mathrm{H}, \mathrm{d}, J=8.4 \mathrm{~Hz}), 5.00(1 \mathrm{H}, \mathrm{d}, J=$ $14.8 \mathrm{~Hz}), 4.56(1 \mathrm{H}$, br. s), $4.04(1 \mathrm{H}, \mathrm{d}, J=14.4 \mathrm{~Hz}), 3.81(3 \mathrm{H}, \mathrm{s}), 3.74(1 \mathrm{H}, \mathrm{s}), 2.87(1 \mathrm{H}, \mathrm{s})$, $2.33(1 \mathrm{H}, \mathrm{dd}, J=14.0 \mathrm{~Hz}, 3.6 \mathrm{~Hz}), 1.80-1.91(3 \mathrm{H}, \mathrm{m}) .{ }^{19} \mathrm{~F} \mathrm{NMR}\left(376 \mathrm{MHz}, \mathrm{CDCl}_{3}\right) \delta-78.19$ $(3 \mathrm{~F}, \mathrm{~s}) . \mathrm{m} / z$ (EI, DCM): $316.1(\mathrm{M}+1)^{+}, 315.1(\mathrm{M})^{+}, 121.1\left(\mathrm{CH}_{3} \mathrm{OC}_{6} \mathrm{H}_{4} \mathrm{CH}_{2}\right)^{+}$. HRMS calcd. For $\mathrm{C}_{15} \mathrm{H}_{16} \mathrm{O}_{3} \mathrm{NF}_{3}$ : 315.1070. Found 315.1077.

(1S,4S,6SR)-6-hydroxyl-6-pentafluoroethyl-2-(4'-methoxybenzyl)-azabicyclo [2.2.1]heptan-3-one (21b)-This compound was synthesized by the same method as for 21a. ${ }^{1} \mathrm{H}$ NMR $\left(400 \mathrm{MHz}, \mathrm{CDCl}_{3}\right) \delta 7.17(2 \mathrm{H}, \mathrm{d}, J=8.8 \mathrm{~Hz}), 6.87(2 \mathrm{H}, \mathrm{d}, J=7.6 \mathrm{~Hz}), 4.98$ $(1 \mathrm{H}, \mathrm{d}, J=15.2 \mathrm{~Hz}), 4.97(1 \mathrm{H}, \mathrm{s}), 4.01(1 \mathrm{H}, \mathrm{d}, J=14.8 \mathrm{~Hz}), 3.86(1 \mathrm{H}, \mathrm{s}), 3.80(3 \mathrm{H}, \mathrm{s}), 2.84$ $(1 \mathrm{H}, \mathrm{s}), 2.42(1 \mathrm{H}, \mathrm{d}, J=13.6 \mathrm{~Hz}), 1.78-1.89(3 \mathrm{H}, \mathrm{m}) .{ }^{19} \mathrm{~F} \mathrm{NMR}\left(376 \mathrm{MHz}, \mathrm{CDCl}_{3}\right) \delta-79.02$ $(3 \mathrm{~F}, \mathrm{~s}),-120.08(2 \mathrm{~F}, a b, J=277.5 \mathrm{~Hz}) . m / z(\mathrm{EI}, \mathrm{DCM}): 366.1(\mathrm{M}+1)^{+}, 365.1(\mathrm{M})^{+}, 121.1$ $\left(\mathrm{CH}_{3} \mathrm{OC}_{6} \mathrm{H}_{4} \mathrm{CH}_{2}\right)^{+} \mathrm{HRMS}$ calcd. For $\mathrm{C}_{16} \mathrm{H}_{16} \mathrm{O}_{3} \mathrm{NF}_{5}$ : 365.1050. Found 365.1045.

(1S,4R,6S)-Toluene-4-sulfonic acid 2-(4-methoxybenzyl)-3-oxo-6trifluoromethyl-2-azabicyclo[2.2.1]hept-6-yl ester (23a)- NaH in mineral oil (14 mg, $60 \%, 0.3 \mathrm{mmol}$ ) was washed with anhydrous pentane, suspended in dry ether $(3 \mathrm{~mL})$, and cooled to $0{ }^{\circ} \mathrm{C}$ in an ice bath. Compound $21 \mathrm{a}(52 \mathrm{mg}, 0.16 \mathrm{mmol})$ in dry ether $(1 \mathrm{~mL})$ was then added dropwise via syringe. The resulting white suspension was stirred at $0{ }^{\circ} \mathrm{C}$ for $15 \mathrm{~min}$ under argon followed by addition of $\mathrm{TsCl}(64 \mathrm{mg}, 0.3 \mathrm{mmol})$ in dry ether $(1 \mathrm{~mL})$. The resulting white suspension was allowed to slowly warm up to room temperature and was stirred under argon for $16 \mathrm{~h}$. Water was added, and the two layers were separated. The aqueous layer was further extracted with ether $(10 \mathrm{~mL} \times 3)$, and the combined ether solutions were washed with brine $(10 \mathrm{~mL} \times 2)$ and concentrated under vacuum. The residue was separated by flash column chromatography on silica gel (hexanes/EtOAc 1:1) to give 23a (58 $\mathrm{mg}, 79 \%)$ as a white solid. ${ }^{1} \mathrm{H}$ NMR $\left(500 \mathrm{MHz}, \mathrm{CDCl}_{3}\right) \delta 7.82(2 \mathrm{H}, \mathrm{d}, J=8.0 \mathrm{~Hz}), 7.40(2 \mathrm{H}, \mathrm{d}, J=6.0 \mathrm{~Hz}), 7.04$ $(2 \mathrm{H}, \mathrm{d}, J=6.4 \mathrm{~Hz}), 6.82(2 \mathrm{H}, \mathrm{d}, J=6.4 \mathrm{~Hz}), 4.75(1 \mathrm{H}, \mathrm{d}, J=12.0 \mathrm{~Hz}), 3.84(1 \mathrm{H}, \mathrm{s}), 3.78(3 \mathrm{H}$, s), $3.43(1 \mathrm{H}, \mathrm{d}, J=12.0 \mathrm{~Hz}), 3.09(1 \mathrm{H}, \mathrm{d}, J=12.0 \mathrm{~Hz}), 2.96(1 \mathrm{H}, \mathrm{s}), 2.47(3 \mathrm{H}, \mathrm{s}), 2.40(1 \mathrm{H}$, dd, $J=12.4 \mathrm{~Hz}, 2.8 \mathrm{~Hz}), 1.81-1.84(2 \mathrm{H}, \mathrm{m}) .{ }^{19} \mathrm{~F} \mathrm{NMR}\left(376 \mathrm{MHz}, \mathrm{CDCl}_{3}\right) \delta-74.41(3 \mathrm{~F}$, s). ${ }^{13} \mathrm{C} \mathrm{NMR}\left(\mathrm{CDCl}_{3}, 125.6 \mathrm{MHz}\right) \delta 175.17,159.24,145.72,134.22,130.13,129.54,128.30$, 127.76, 123.16 (q), 114.21, 63.32, 55.31, 45.83, 45.03, 39.13, 31.11, 21.80.

(1S,4R,6S)-Toluene-4-sulfonic acid 2-(4-methoxybenzyl)-3-oxo-6pentafluoroethyl-2-azabicyclo [2.2.1] hept-6-yl ester (23b)-This compound was synthesized from $21 \mathbf{b}$ similar to the synthesis of $23 \mathbf{a} .{ }^{1} \mathrm{H}$ NMR $\left(400 \mathrm{MHz}, \mathrm{CDCl}_{3}\right) \delta 7.84(2 \mathrm{H}$, d, $J=8.0 \mathrm{~Hz}), 7.40(2 \mathrm{H}, \mathrm{d}, J=8.8 \mathrm{~Hz}), 7.04(2 \mathrm{H}, \mathrm{d}, J=8.4 \mathrm{~Hz}), 6.83(2 \mathrm{H}, \mathrm{d}, J=8.0 \mathrm{~Hz}), 4.95$ $(1 \mathrm{H}, \mathrm{d}, J=15.6 \mathrm{~Hz}), 3.90(1 \mathrm{H}, \mathrm{s}), 3.78(3 \mathrm{H}, \mathrm{s}), 3.54(1 \mathrm{H}, \mathrm{d}, J=14.8 \mathrm{~Hz}), 3.29(1 \mathrm{H}, \mathrm{d}, J=15.6$ $\mathrm{Hz}), 2.96(1 \mathrm{H}, \mathrm{s}), 2.48-2.51(4 \mathrm{H}, \mathrm{m}), 1.85(1 \mathrm{H}, \mathrm{d}, J=11.2 \mathrm{~Hz}), 1.79(1 \mathrm{H}, \mathrm{d}, J=10.4$

Hz). ${ }^{19} \mathrm{~F} \mathrm{NMR}\left(376 \mathrm{MHz}, \mathrm{CDCl}_{3}\right) \delta-78.99(3 \mathrm{~F}, \mathrm{~s}),-116.41(2 \mathrm{~F}, \mathrm{ab}) .{ }^{13} \mathrm{C} \mathrm{NMR}\left(\mathrm{CDCl}_{3}, 125.6\right.$ MHz) $\delta 174.98,159.22,145.86,133.85,130.04,129.62,127.98,114.21,63.21,55.33,46.13$, 44.59, 30.77, 21.87. $\mathrm{m} / z$ (EI, MeOH): $519.0(\mathrm{M})^{+}, 520.0(\mathrm{M}+1)^{+}, 365(\mathrm{M}-$

$\left.\mathrm{CH}_{3} \mathrm{C}_{6} \mathrm{H}_{4} \mathrm{SO}_{2}\right)^{+}$, 121.0. HRMS calcd. For $\mathrm{C}_{23} \mathrm{H}_{22} \mathrm{O}_{5} \mathrm{NF}_{5} \mathrm{~S}$ : 519.183. Found 519.1135.

(1S,4R)-6-Trifluoromethyl-2-(4-methoxybenzyl)-2-azabicyclo[2.2.1]hept-5-en-3one (22a). General procedure l-Methyl fluorosulfonyldifluoroacetate (MFSDA; $48 \mathrm{mg}$, $0.25 \mathrm{mmol})$ in anhydrous DMF $(1 \mathrm{~mL})$ was added dropwise via syringe to a suspension of 
17 (35.5 mg, $0.1 \mathrm{mmol})$ and CuI (23 mg, $0.12 \mathrm{mmol})$ in anhydrous DMF (2 mL) and HMPA $(1 \mathrm{~mL})$ at $75^{\circ} \mathrm{C}$ under argon over a period of $1 \mathrm{~h}$. The resulting suspension was stirred at $75^{\circ}$ $\mathrm{C}$ under argon for $72 \mathrm{~h}$ and evaporated under high vacuum. The residue was purified via column chromatography on silica gel (hexanes/EtOAc 3:1) to give 22a $(22.1 \mathrm{mg}, 75 \%$ ) as a light brown oil. ${ }^{1} \mathrm{H}$ NMR $\left(500 \mathrm{MHz}, \mathrm{CDCl}_{3}\right) \delta 7.18(2 \mathrm{H}, \mathrm{d}, J=8.5 \mathrm{~Hz}), 7.11(1 \mathrm{H}, \mathrm{s}), 6.89(2 \mathrm{H}, \mathrm{d}, J=8.5$ $\mathrm{Hz}), 4.77(1 \mathrm{H}, \mathrm{d}, J=15.0 \mathrm{~Hz}), 4.23(1 \mathrm{H}, \mathrm{s}), 3.82(3 \mathrm{H}, \mathrm{s}), 3.56(1 \mathrm{H}, \mathrm{s}), 3.54(1 \mathrm{H}, \mathrm{d}, J=15.0$ $\mathrm{Hz}), 2.40(1 \mathrm{H}, \mathrm{d}, J=8.0 \mathrm{~Hz}), 2.32(1 \mathrm{H}, \mathrm{d}, J=8.0 \mathrm{~Hz}) .{ }^{19} \mathrm{~F}$ NMR $\left(376.49 \mathrm{MHz}, \mathrm{CDCl}_{3}\right) \delta$ $-64.69(3 \mathrm{~F}, \mathrm{~s}) .{ }^{13} \mathrm{C} \mathrm{NMR}\left(\mathrm{CDCl}_{3}, 125.6 \mathrm{MHz}\right) \delta 178.04,159.30,143.97\left(\mathrm{q}, J_{C F}=36.6 \mathrm{~Hz}\right)$, $141.52\left(\mathrm{q}, J_{C F}=5.4 \mathrm{~Hz}\right), 129.54,128.26,122.44\left(\mathrm{q}, J_{C F}=267.8 \mathrm{~Hz}\right), 114.25,61.35,59.31$, 55.35, 54.06, 46.81. $\mathrm{m} / z(\mathrm{EI}, \mathrm{MeOH}): 297.1(\mathrm{M})^{+}, 298.1(\mathrm{M}+1)^{+}, 163.1(\mathrm{M}-\mathrm{PMBN})^{+}, 121.0$ $(\mathrm{PMB})^{+}$. HRMS calcd. For $\mathrm{C}_{15} \mathrm{H}_{14} \mathrm{O}_{2} \mathrm{NF}_{3}$ : 297.0971. Found 297.0970.

(1S,4R)-6-Trifluoromethyl-2-azabicyclo[2.2.1] hept-5-en-3-one (24a). General procedure II-Ceric ammonium nitrate (CAN; $1.38 \mathrm{~g}, 2.525 \mathrm{mmol})$ in water $(3 \mathrm{~mL})$ was added to a solution of 22a $(150 \mathrm{mg}, 0.505 \mathrm{mmol})$ in acetonitrile $(6 \mathrm{~mL})$. The resulting red solution was stirred at room temperature for $1.5 \mathrm{~h}$. The reaction mixture was diluted with ethyl acetate, washed with saturated aq. $\mathrm{NaHCO}_{3}$, then brine, and dried over anhydrous $\mathrm{MgSO}_{4}$. The solution was concentrated under vacuum, and the residue was purified via column chromatography on silica gel (hexanes/EtOAc 1:1) to give $\mathbf{2 4 a}(54 \mathrm{mg}, 61 \%)$ as a white solid. ${ }^{1} \mathrm{H}$ NMR $\left(500 \mathrm{MHz}, \mathrm{CDCl}_{3}\right) \delta 7.07(1 \mathrm{H}, \mathrm{s}), 6.15(1 \mathrm{H}, \mathrm{br} . \mathrm{s}), 4.51(1 \mathrm{H}, \mathrm{s}), 3.42(1 \mathrm{H}, \mathrm{s})$, $2.54(1 \mathrm{H}, \mathrm{d}, J=8.0 \mathrm{~Hz}), 2.43(1 \mathrm{H}, \mathrm{d}, J=8.0 \mathrm{~Hz}) .{ }^{19} \mathrm{~F} \mathrm{NMR}\left(376 \mathrm{MHz}, \mathrm{CDCl}_{3}\right) \delta-66.42(3 \mathrm{~F}$, s). ${ }^{13} \mathrm{C} \mathrm{NMR}\left(\mathrm{CDCl}_{3}, 125.6 \mathrm{MHz}\right) \delta 182.3,144.3(\mathrm{~m}), 141.0\left(\mathrm{q}, J_{F C}=5.5 \mathrm{~Hz}\right), 122.4(\mathrm{q}$, $\left.J_{F C}=268.2 \mathrm{~Hz}\right), 60.1,58.6,53.7 . \mathrm{m} / \mathrm{z}(\mathrm{CI}, \mathrm{MeOH}): 178.3(\mathrm{M}+1)^{+}, 115.2$. HRMS calcd. for $\mathrm{C}_{7} \mathrm{H}_{7} \mathrm{ONF}_{3}(\mathrm{M}+\mathrm{H}):$ 178.0474. Found 178.0481 .

(1R,4S)-4-Amino-3-trifluoromethyl-cyclopent-2-ene carboxylic acid (6). General procedure III-Compound $24 a$ ( $44 \mathrm{mg}, 0.249 \mathrm{mmol}$ ) was dissolved in $4 \mathrm{~N}$ aq. $\mathrm{HCl}(5 \mathrm{~mL}$ ), and the resulting clear solution was heated to 70 to $75^{\circ} \mathrm{C}$ and stirred for 40 to $45 \mathrm{~min}$. The resulting colorless clear solution was extracted with EtOAc $(3 \mathrm{~mL} \times 2)$ and evaporated to dryness under high vacuum to give the crude product, which was further purified via ion exchange chromatography $(0.15 \mathrm{~N}$ aq. $\mathrm{HCl}$ as eluant) to give 6 as a white solid $(49 \mathrm{mg}, 85 \%)$, $\mathrm{mp} 195.0-196.0{ }^{\circ} \mathrm{C} ;{ }^{1} \mathrm{H}$ NMR $\left(\mathrm{D}_{2} \mathrm{O}, 400.169 \mathrm{MHz}\right) \delta 6.96(1 \mathrm{H}, \mathrm{s}), 4.69(1 \mathrm{H}, \mathrm{s}), 3.92(1 \mathrm{H}, \mathrm{s})$, 2.87-2.95 (1H, m), 2.29-2.35 (1H, m). ${ }^{19} \mathrm{~F} \mathrm{NMR}\left(\mathrm{D}_{2} \mathrm{O}, 376.493 \mathrm{MHz}\right) \delta-64.35(3 \mathrm{~F}, \mathrm{~s}) .{ }^{13} \mathrm{C}$ $\operatorname{NMR}\left(\mathrm{D}_{2} \mathrm{O}, 125.614 \mathrm{MHz}\right) \delta 175.12,142.54\left(\mathrm{q}, J_{F C}=4.6 \mathrm{~Hz}\right), 130.82\left(\mathrm{q}, J_{F C}=33.7 \mathrm{~Hz}\right)$, $121.62\left(\mathrm{q}, J_{F C}=269.7 \mathrm{~Hz}\right), 53.64,48.80,32.11 . \mathrm{m} / z(\mathrm{EI}, \mathrm{MeOH}): 196.1(\mathrm{M})^{+}, 179.1(\mathrm{M}-$ $\mathrm{OH})^{+}, 159.1$. HRMS calcd. For $\mathrm{C}_{7} \mathrm{H}_{9} \mathrm{O}_{2} \mathrm{NF}_{3}$ : 196.0580. Found 196.0576. Anal. $\left(\mathrm{C}_{7} \mathrm{H}_{9} \mathrm{O}_{2} \mathrm{NF}_{3}\right) \mathrm{C}, \mathrm{H}, \mathrm{N}$.

(1S,4R)-6-Pentafluoroethyl-2-(4-methoxybenzyl)-2-azabicyclo[2.2.1]hept-5en-3-one (22b)-A $5 \mathrm{~mL}$ screw-capped Pyrex tube was charged with CuI (19 mg, 0.10 $\mathrm{mmol}), \mathrm{KF}(14.5 \mathrm{mg}, 0.25 \mathrm{mmol})$, and a stirring bar. The tube was dried with a heat gun under vacuum for $20 \mathrm{~min}$ and filled with argon. Compound $17(18 \mathrm{mg}, 0.05 \mathrm{mmol})$ in anhydrous NMP $(1 \mathrm{~mL})$ was added via syringe to the above reaction tube followed by $\mathrm{TMSC}_{2} \mathrm{~F}_{5}(48 \mathrm{mg}$, $0.25 \mathrm{mmol})$ in anhydrous DMF $(1 \mathrm{~mL})$. The resulting suspension was heated to $80^{\circ} \mathrm{C}$ and stirred vigorously for $48 \mathrm{~h}$. The reaction mixture was then evaporated under high vacuum, and the residue was purified via column chromatography on silica gel (hexanes/EtOAc 3:1) to give 22b (10 mg, 57\%) as a light yellow oil. ${ }^{1} \mathrm{H}$ NMR $\left(400.168 \mathrm{MHz}, \mathrm{CDCl}_{3}\right) \delta 7.17-7.19(3 \mathrm{H}$, $\mathrm{m}), 6.89(2 \mathrm{H}, \mathrm{d}, J=8.8 \mathrm{~Hz}), 4.80(1 \mathrm{H}, \mathrm{d}, J=15.2 \mathrm{~Hz}), 4.26(1 \mathrm{H}, \mathrm{s}), 3.82(3 \mathrm{H}, \mathrm{s}), 3.60(1 \mathrm{H}$, s), $3.52(1 \mathrm{H}, \mathrm{d}, J=14.4 \mathrm{~Hz}), 2.40(1 \mathrm{H}, \mathrm{d}, J=6.4 \mathrm{~Hz}), 2.32(1 \mathrm{H}, \mathrm{d}, J=8.0 \mathrm{~Hz}) .{ }^{19} \mathrm{~F}$ NMR $\left(376.49 \mathrm{MHz}, \mathrm{CDCl}_{3}\right) \delta-84.12(3 \mathrm{~F}, \mathrm{~s}),-113.67\left(2 \mathrm{~F}, \mathrm{ab}, J_{a b}=279.4 \mathrm{~Hz}\right) .{ }^{13} \mathrm{C} \mathrm{NMR}\left(\mathrm{CDCl}_{3}\right.$, $125.6 \mathrm{MHz}) \delta 177.59,159.30,144.14\left(\mathrm{t}, J_{C F}=8.0 \mathrm{~Hz}\right), 143.03\left(\mathrm{t}, J_{C F}=26.0 \mathrm{~Hz}\right), 129.51$, $128.21,118.81\left(\mathrm{dt}, J_{C F}=285.4 \mathrm{~Hz}, 37.8 \mathrm{~Hz}\right), 114.24,61.90,59.79,55.32,54.54,46.64 . \mathrm{m} / \mathrm{z}$ 
(EI, DCM): $347.1(\mathrm{M})^{+}, 121.0(\mathrm{PMB})^{+}$. HRMS calcd. For $\mathrm{C}_{16} \mathrm{H}_{14} \mathrm{O}_{2} \mathrm{NF}_{5}$ : 347.0939. Found 347.0933 .

(1S,4R)-6-Pentafluoroethyl-2-azabicyclo[2.2.1]hept-5-en-3-one (24b)-was synthesized from $22 \mathrm{~b}$ in a yield of $74 \%$ using general procedure II. ${ }^{1} \mathrm{H}$ NMR $(500 \mathrm{MHz}$, $\left.\mathrm{CDCl}_{3}\right) \delta 7.14(1 \mathrm{H}, \mathrm{s}), 6.64(1 \mathrm{H}$, br. s), $4.52(1 \mathrm{H}, \mathrm{s}), 3.43(1 \mathrm{H}, \mathrm{s}), 2.52(1 \mathrm{H}, \mathrm{d}, J=7.0 \mathrm{~Hz})$, $2.41(1 \mathrm{H}, \mathrm{d}, J=7.0 \mathrm{~Hz}) .{ }^{19} \mathrm{~F} \mathrm{NMR}\left(376 \mathrm{MHz}, \mathrm{CDCl}_{3}\right) \delta-84.45(3 \mathrm{~F}, \mathrm{~s}),-116.41\left(2 \mathrm{~F}, \mathrm{ab}, J_{a b}=\right.$ $276.3 \mathrm{~Hz}, \Delta v=268 . \mathrm{h} \mathrm{Hz}) .{ }^{13} \mathrm{C} \mathrm{NMR}\left(\mathrm{CDCl}_{3}, 125.6 \mathrm{MHz}\right) \delta 182.28,143.40-143.78(\mathrm{~m}, 2 \mathrm{C})$, $111.80-122.15\left(\mathrm{~m}, 2 \mathrm{C}, \mathrm{C}_{2} \mathrm{~F}_{5}\right), 60.72,59.23,54.13 . \mathrm{m} / \mathrm{z}(\mathrm{CI}, \mathrm{DCM}): 228.0(\mathrm{M}+1)^{+}, 185.3(\mathrm{M}-$ $\mathrm{CON})^{+}, 165.3(\mathrm{M}-\mathrm{CONH}-\mathrm{F})^{+}$. HRMS calcd. For $\mathrm{C}_{16} \mathrm{H}_{14} \mathrm{O}_{2} \mathrm{NF}_{5}$ : 347.0939. Found 347.0933.

(1R,4S)-4-Amino-3-pentafluoroethyl-cyclopent-2-ene carboxylic acid (7)-was synthesized using general procedure III from $\mathbf{2 4} \mathbf{b}$ as a white solid in a yield of $82 \%, \mathrm{mp}$ 187.0-188.5 ${ }^{\circ} \mathrm{C}^{;}{ }^{1} \mathrm{H}$ NMR $\left(\mathrm{D}_{2} \mathrm{O}, 499.511 \mathrm{MHz}\right) \delta 7.00(1 \mathrm{H}, \mathrm{s}), 4.71(1 \mathrm{H}, \mathrm{d}, J=3.5 \mathrm{~Hz}), 3.92$ $(1 \mathrm{H}, \mathrm{s}), 2.85-2.91(1 \mathrm{H}, \mathrm{m}), 2.29-2.33(1 \mathrm{H}, \mathrm{m}) .{ }^{19} \mathrm{~F}$ NMR $\left(\mathrm{D}_{2} \mathrm{O}, 376.493 \mathrm{MHz}\right) \delta-84.60(3 \mathrm{~F}$, $\mathrm{t}, J=18.8 \mathrm{~Hz}),-113.07(2 \mathrm{~F}, \mathrm{ab}, J=283.9 \mathrm{~Hz}, \Delta=62.5 \mathrm{~Hz}) .{ }^{13} \mathrm{C} \mathrm{NMR}\left(\mathrm{D}_{2} \mathrm{O}, 125.614 \mathrm{MHz}\right)$ $\delta 174.89,145.37\left(\mathrm{t}, J_{F C}=7.2 \mathrm{~Hz}\right), 129.63\left(\mathrm{t}, J_{F C}=25.0 \mathrm{~Hz}\right), 109.70-119.59(2 \mathrm{C}, \mathrm{m}), 54.61$, 49.27, 32.10. $\mathrm{m} / z$ (EI, MeOH): $246.1(\mathrm{M}+1)^{+}, 245.1(\mathrm{M})^{+}, 200.1\left(\mathrm{M}-\mathrm{CO}_{2} \mathrm{H}\right)^{+}, 176.1$. HRMS calcd. For $\mathrm{C}_{8} \mathrm{H}_{8} \mathrm{O}_{2} \mathrm{NF}_{5}$ : 245.0470. Found 245.0475. Anal. $\left(\mathrm{C}_{8} \mathrm{H}_{8} \mathrm{O}_{2} \mathrm{NF}_{5} .1 .5 \mathrm{H}_{2} \mathrm{O}\right) \mathrm{C}, \mathrm{H}, \mathrm{N}$.

(1S,4R)-6-Bromomethylene-2-(4-methoxybenzyl)-2-azabicyclo[2.2.1]heptan-3one (25)-(Bromomethyl)triphenylphosphonium bromide $(0.567 \mathrm{~g}, 1.3 \mathrm{mmol})$ was suspended in dry THF $(4 \mathrm{~mL})$, cooled to $-78{ }^{\circ} \mathrm{C}$, and then treated by addition of tert-BuOK (1.0 M in THF, $1.2 \mathrm{~mL}, 1.2 \mathrm{mmol})$. The resulting brown suspension was stirred at $-78{ }^{\circ} \mathrm{C}$ for $1.5 \mathrm{~h}$ and then treated with $\mathbf{1 6}(0.246 \mathrm{~g}, 1.0 \mathrm{mmol})$ in dry THF $(1 \mathrm{~mL})$. The resulting light brown mixture was allowed to gradually warm up to room temperature and was stirred overnight. The reaction was quenched via addition of water, and the mixture was extracted with dichloromethane $(10 \mathrm{~mL} \times 3)$. The combined organic layers were washed with brine $(20$ $\mathrm{mL} \times 2$ ) and dried over anhydrous $\mathrm{MgSO}_{4}$. The solvent was removed under vacuum, and the residue was purified via column chromatography on silica gel (hexanes/EtOAc 1:1) to give 25a (Z-isomer, $100 \mathrm{mg}, 31 \%$ ) as a light yellow oil and $\mathbf{2 5 b}$ ( $E$-isomer, $131 \mathrm{mg}, 41 \%)$ as a white solid.

25a: ${ }^{1} \mathrm{H}$ NMR (500MHz, $\left.\mathrm{CDCl}_{3}\right) \delta 7.26(2 \mathrm{H}, \mathrm{d}, J=8.0 \mathrm{~Hz}), 6.88(2 \mathrm{H}, \mathrm{d}, J=8.0 \mathrm{~Hz}), 6.01$ $(1 \mathrm{H}, \mathrm{s}), 4.76(1 \mathrm{H}, \mathrm{d}, J=15.0 \mathrm{~Hz}), 4.35(1 \mathrm{H}, \mathrm{s}), 3.81(3 \mathrm{H}, \mathrm{s}), 3.70(1 \mathrm{H}, \mathrm{d}, J=15.0 \mathrm{~Hz}), 3.02$ $(1 \mathrm{H}, \mathrm{s}), 2.47(1 \mathrm{H}, \mathrm{d}, J=16.0 \mathrm{~Hz}), 2.31(1 \mathrm{H}, \mathrm{d}, J=15.5 \mathrm{~Hz}), 1.97(1 \mathrm{H}, \mathrm{d}, J=9.5 \mathrm{~Hz}), 1.54$ $(1 \mathrm{H}, \mathrm{d}, J=10.0 \mathrm{~Hz}) .{ }^{13} \mathrm{C} \mathrm{NMR}\left(126 \mathrm{MHz}, \mathrm{CDCl}_{3}\right) \delta 177.51,159.15,143.88,129.64,128.94$, 114.01, 97.82, 61.88, 55.31, 45.81, 44.36, 39.78, 32.77. $\mathrm{m} / z(\mathrm{ESI}, \mathrm{MeOH}): 344.6(\mathrm{M}+\mathrm{Na})^{+}$, $346.5(\mathrm{M}+2+\mathrm{Na})^{+}$. HRMS calcd. For $\mathrm{C}_{15} \mathrm{H}_{16} \mathrm{O}_{2} \mathrm{NBr}$ : 321.0359. Found 321.0359.

25b: ${ }^{1} \mathrm{H}$ NMR $\left(500 \mathrm{MHz}, \mathrm{CDCl}_{3}\right) \delta 7.14(2 \mathrm{H}, \mathrm{d}, J=8.5 \mathrm{~Hz}), 6.86(2 \mathrm{H}, \mathrm{d}, J=8.5 \mathrm{~Hz}), 6.10$ $(1 \mathrm{H}, \mathrm{s}), 4.62(1 \mathrm{H}, \mathrm{d}, J=15.0 \mathrm{~Hz}), 3.86(1 \mathrm{H}, \mathrm{s}), 3.80(3 \mathrm{H}, \mathrm{s}), 3.79(1 \mathrm{H}, \mathrm{d}, J=15.0 \mathrm{~Hz}), 2.97$ $(1 \mathrm{H}, \mathrm{s}), 2.43(1 \mathrm{H}, \mathrm{dt}, J=16.5 \mathrm{~Hz}, 3.0 \mathrm{~Hz}), 2.26(1 \mathrm{H}, \mathrm{d}, J=16.5 \mathrm{~Hz}), 2.06(1 \mathrm{H}, \mathrm{d}, J=9.5 \mathrm{~Hz})$, $1.60(1 \mathrm{H}, \mathrm{d}, J=9.5 \mathrm{~Hz}) .{ }^{13} \mathrm{C} \mathrm{NMR}\left(126 \mathrm{MHz}, \mathrm{CDCl}_{3}\right) \delta 177.79,159.19,144.28,129.42,128.53$, 114.15, 100.00, 63.46, 55.33, 44.89, 43.95, 41.16, 33.49. m/z (ESI, MeOH): $344.6(\mathrm{M}+$ $\mathrm{Na})^{+}, 346.2(\mathrm{M}+2+\mathrm{Na})^{+}$. HRMS calcd. For $\mathrm{C}_{15} \mathrm{H}_{16} \mathrm{O}_{2} \mathrm{NBr}$ : 321.0359. Found 321.0359.

(Z)-(1S,4R)-2-(4-Methoxybenzyl)-6-(2,2,2-trifluoro-ethylidene)-2-azabicyclo [2.2.1] heptan-3-one (26a) - was synthesized in a 95\% yield from $\mathbf{2 5 a}$ using general procedure I (reaction time $20 \mathrm{~h}) .{ }^{1} \mathrm{H}$ NMR $\left(400 \mathrm{MHz}, \mathrm{CDCl}_{3}\right) \delta 7.18(2 \mathrm{H}, \mathrm{d}, J=8.8 \mathrm{~Hz}), 6.88$ $(2 \mathrm{H}, \mathrm{d}, J=8.4 \mathrm{~Hz}), 5.68(1 \mathrm{H}, \mathrm{q}, J=8.0 \mathrm{~Hz}), 4.81(1 \mathrm{H}, \mathrm{d}, J=14.8 \mathrm{~Hz}), 4.44(1 \mathrm{H}, \mathrm{s}), 3.82(1 \mathrm{H}$, s), $3.58(1 \mathrm{H}, \mathrm{d}, J=15.2 \mathrm{~Hz}), 2.95(1 \mathrm{H}, \mathrm{s}), 2.57(1 \mathrm{H}, \mathrm{d}, J=17.2 \mathrm{~Hz}), 2.41(1 \mathrm{H}, \mathrm{d}, J=17.2 \mathrm{~Hz})$, 
$2.06(1 \mathrm{H}, \mathrm{d}, J=8.8 \mathrm{~Hz}), 1.58(1 \mathrm{H}, \mathrm{d}, J=10.4 \mathrm{~Hz}) .{ }^{19} \mathrm{~F} \mathrm{NMR}\left(376.49 \mathrm{MHz}, \mathrm{CDCl}_{3}\right) \delta-58.02$ (3F, m). $\mathrm{m} / z$ (EI, DCM): $311.1(\mathrm{M})^{+}, 312.1(\mathrm{M}+1)^{+}, 121.0(\mathrm{PMB})^{+}$. HRMS calcd. For $\mathrm{C}_{16} \mathrm{H}_{16} \mathrm{O}_{2} \mathrm{NF}_{3}: 311.1128$. Found 311.1133 .

(E)-(1S,4R)-2-(4-Methoxybenzyl)-6-(2,2,2-trifluoroethylidene)-2-azabicyclo [2.2.1] heptan-3-one (26b) -was synthesized in a 95\% yield from $\mathbf{2 5 b}$ using general procedure I (reaction time $20 \mathrm{~h}) .{ }^{1} \mathrm{H}$ NMR $\left(400 \mathrm{MHz}, \mathrm{CDCl}_{3}\right) \delta 7.15(2 \mathrm{H}, \mathrm{d}, J=8.8 \mathrm{~Hz}), 6.87$ $(2 \mathrm{H}, \mathrm{d}, J=8.4 \mathrm{~Hz}), 5.51(1 \mathrm{H}, \mathrm{q}, J=7.2 \mathrm{~Hz}), 4.57(1 \mathrm{H}, \mathrm{d}, J=14.4 \mathrm{~Hz}), 3.90(1 \mathrm{H}, \mathrm{d}, J=15.2$ $\mathrm{Hz}), 3.86(1 \mathrm{H}, \mathrm{s}), 3.80(3 \mathrm{H}, \mathrm{s}), 2.98(1 \mathrm{H}, \mathrm{s}), 2.62(1 \mathrm{H}, \mathrm{dq}, J=17.2 \mathrm{~Hz}, 2.4 \mathrm{~Hz}), 2.48(1 \mathrm{H}, \mathrm{dq}$, $J=17.2 \mathrm{~Hz}, 2.4 \mathrm{~Hz}), 2.05(1 \mathrm{H}, \mathrm{d}, J=9.2 \mathrm{~Hz}), 1.56(1 \mathrm{H}, \mathrm{d}, J=10.0 \mathrm{~Hz}) .{ }^{19} \mathrm{~F}$ NMR $(376.49$ $\left.\mathrm{MHz}, \mathrm{CDCl}_{3}\right) \delta-60.98(3 \mathrm{~F}, \mathrm{~m}) . \mathrm{m} / z(\mathrm{EI}, \mathrm{DCM}): 311.1(\mathrm{M})^{+}, 312.1(\mathrm{M}+1)^{+}, 121.0(\mathrm{PMB})^{+}$. HRMS calcd. For $\mathrm{C}_{16} \mathrm{H}_{16} \mathrm{O}_{2} \mathrm{NF}_{3}: 311.1128$. Found 311.1133.

(Z)-(1S,4R)-6-(2,2,2-Trifluoroethylidene)-2-azabicyclo[2.2.1]heptan-3-one (27a) - was synthesized in a 74\% yield from 26a using general procedure II. ${ }^{1} \mathrm{H}$ NMR $(400 \mathrm{MHz}$, $\left.\mathrm{CDCl}_{3}\right) \delta 6.30(1 \mathrm{H}, \mathrm{s}), 5.58(1 \mathrm{H}, \mathrm{q}, J=8.0 \mathrm{~Hz}), 4.61(1 \mathrm{H}, \mathrm{s}), 2.83(1 \mathrm{H}, \mathrm{s}), 2.55(1 \mathrm{H}, \mathrm{d}, J=$ $17.2 \mathrm{~Hz}), 2.36(1 \mathrm{H}, \mathrm{d}, J=16.4 \mathrm{~Hz}), 2.18(1 \mathrm{H}, \mathrm{dd}, J=10.4 \mathrm{~Hz}, 1.2 \mathrm{~Hz}), 1.63(1 \mathrm{H}, \mathrm{d}, J=9.6$ $\mathrm{Hz}) .{ }^{19} \mathrm{~F} \mathrm{NMR}\left(376 \mathrm{MHz}, \mathrm{CDCl}_{3}\right) \delta-58.28(3 \mathrm{~F}, \mathrm{~m}) .{ }^{13} \mathrm{C} \mathrm{NMR}\left(\mathrm{CDCl}_{3}, 125.6 \mathrm{MHz}\right) \delta 179.92$, $152.44\left(\mathrm{q}, J_{F C}=5.5 \mathrm{~Hz}\right), 122.93\left(\mathrm{q}, J_{F C}=270.1 \mathrm{~Hz}\right), 110.02\left(\mathrm{q}, J_{F C}=34.8 \mathrm{~Hz}\right), 56.67,43.58$, 41.49, 32.23. $\mathrm{m} / z$ (EI, DCM): $192(\mathrm{M}+1)^{+}, 191(\mathrm{M})^{+}, 79.1$. HRMS calcd. for $\mathrm{C}_{8} \mathrm{H}_{8} \mathrm{ONF}_{3}$ : 191.0553. Found 191.0559.

(E)-(1S,4R)-6-(2,2,2-Trifluoroethylidene)-2-azabicyclo[2.2.1] heptan-3-one (27b) -was synthesized in a 74\% yield from 26a using general procedure II. ${ }^{1} \mathrm{H}$ NMR $(400 \mathrm{MHz}$, $\left.\mathrm{CDCl}_{3}\right) \delta 6.57(1 \mathrm{H}, \mathrm{s}), 5.77(1 \mathrm{H}, \mathrm{d}, J=7.6 \mathrm{~Hz}), 4.13(1 \mathrm{H}, \mathrm{s}), 2.87(1 \mathrm{H}, \mathrm{s}), 2.65(1 \mathrm{H}, \mathrm{d}, J=$ $16.0 \mathrm{~Hz}), 2.48(1 \mathrm{H}, \mathrm{d}, J=16.8 \mathrm{~Hz}), 2.14(1 \mathrm{H}, \mathrm{d}, J=9.6 \mathrm{~Hz}), 1.62(1 \mathrm{H}, \mathrm{d}, J=9.6 \mathrm{~Hz}) .{ }^{19} \mathrm{~F}$ NMR $\left(376 \mathrm{MHz}, \mathrm{CDCl}_{3}\right) \delta-61.08(3 \mathrm{~F}, \mathrm{~m}) .{ }^{13} \mathrm{C} \mathrm{NMR}\left(\mathrm{CDCl}_{3}, 125.6 \mathrm{MHz}\right) \delta 180.27,151.69$ $\left(\mathrm{q}, J_{F C}=4.6 \mathrm{~Hz}\right), 123.20\left(\mathrm{q}, J_{F C}=270.1 \mathrm{~Hz}\right), 110.82\left(\mathrm{q}, J_{F C}=35.7 \mathrm{~Hz}\right), 60.10,44.60,41.52$, 30.53. $\mathrm{m} / z$ (EI, DCM): $192(\mathrm{M}+1)^{+}, 191(\mathrm{M})^{+}, 163(\mathrm{M}-\mathrm{CO})^{+}, 79$. HRMS calcd. for $\mathrm{C}_{8} \mathrm{H}_{8} \mathrm{ONF}_{3}$ : 191.0553. Found 191.0553.

(1S,3S)-(Z)-3-Amino-4-(2,2,2-trifluoroethylidene)cyclopentane carboxylic acid (8) - was synthesized in a 66\% yield as a white solid from 27a using general procedure III; mp 212.0-214.0 ${ }^{\circ} \mathrm{C} ;{ }^{1} \mathrm{H}$ NMR $\left(\mathrm{D}_{2} \mathrm{O}, 499.511 \mathrm{MHz}\right) \delta 5.97(1 \mathrm{H}, \mathrm{q}, J=7.5 \mathrm{~Hz}), 4.37(1 \mathrm{H}, \mathrm{s})$, 3.09-3.16 (2H, m), 2.92-2.95 (1H, m), 2.56-2.62 (1H, m), $1.98(1 \mathrm{H}, \mathrm{q}, J=12.5 \mathrm{~Hz}) .{ }^{19} \mathrm{~F}$ NMR $\left(\mathrm{D}_{2} \mathrm{O}, 376.493 \mathrm{MHz}\right) \delta-60.78\left(3 \mathrm{~F}, \mathrm{~d}, J_{H F}=6.0 \mathrm{~Hz}\right) .{ }^{13} \mathrm{C} \mathrm{NMR}\left(\mathrm{D}_{2} \mathrm{O}, 125.614 \mathrm{MHz}\right) \delta 177.93$, $150.92\left(\mathrm{q}, J_{F C}=5.0 \mathrm{~Hz}\right), 123.11\left(\mathrm{q}, J_{F C}=270.2 \mathrm{~Hz}\right), 114.77\left(\mathrm{q}, J_{F C}=35.3 \mathrm{~Hz}\right), 53.76,40.69$,

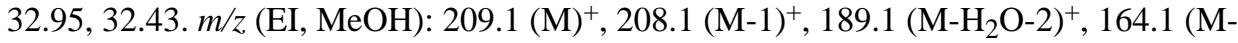
$\left.\mathrm{CO}_{2} \mathrm{H}\right)^{+}$. HRMS calcd. For $\mathrm{C}_{8} \mathrm{H}_{10} \mathrm{O}_{2} \mathrm{NF}_{3}: 209.0658$. Found 277.0656. Anal. $\left(\mathrm{C}_{8} \mathrm{H}_{10} \mathrm{O}_{2} \mathrm{NF}_{3} \cdot 0.25 \mathrm{H}_{2} \mathrm{O}\right) \mathrm{C}, \mathrm{H}, \mathrm{N}$.

(1S,3S)-(Z)-3-Amino-4-(2,2,2-trifluoroethylidene)cyclopentane carboxylic acid (9)-was synthesized from $\mathbf{2 7 b}$ in a $79 \%$ yield as a white solid using general procedure III; mp 206.0-207.5 ${ }^{\circ} \mathrm{C} ;{ }^{1} \mathrm{H}$ NMR $\left(\mathrm{D}_{2} \mathrm{O}, 499.749 \mathrm{MHz}\right) \delta 6.09(1 \mathrm{H}, \mathrm{qd}, J=9.0 \mathrm{~Hz}, 1.5 \mathrm{~Hz}), 4.65$ $(1 \mathrm{H}, \mathrm{s}), 3.02-3.09(1 \mathrm{H}, \mathrm{m}), 2.91-2.92(2 \mathrm{H}, \mathrm{m}), 2.57-2.63(1 \mathrm{H}, \mathrm{m}), 2.13-2.18(1 \mathrm{H}, \mathrm{m}) .{ }^{19} \mathrm{~F} \mathrm{NMR}$ $\left(\mathrm{D}_{2} \mathrm{O}, 376.493 \mathrm{MHz}\right) \delta-60.37\left(3 \mathrm{~F}, \mathrm{~d}, J_{H F}=7.9 \mathrm{~Hz}\right) .{ }^{13} \mathrm{C} \mathrm{NMR}\left(\mathrm{D}_{2} \mathrm{O}, 125.673 \mathrm{MHz}\right) \delta 178.64$, $149.42\left(\mathrm{q}, J_{F C}=5.4 \mathrm{~Hz}\right), 120.43\left(\mathrm{q}, J_{F C}=269.3 \mathrm{~Hz}\right), 116.73\left(\mathrm{q}, J_{F C}=34.3 \mathrm{~Hz}\right), 50.15,40.74$, 37.00, 34.44. $\mathrm{m} / \mathrm{z}(\mathrm{EI}, \mathrm{MeOH}): 210.1(\mathrm{M}+1)^{+}, 209.1(\mathrm{M})^{+}, 191.1\left(\mathrm{M}-\mathrm{H}_{2} \mathrm{O}\right)^{+}, 164.1(\mathrm{M}-$ $\left.\mathrm{CO}_{2} \mathrm{H}\right)^{+}$. HRMS calcd. For $\mathrm{C}_{8} \mathrm{H}_{10} \mathrm{O}_{2} \mathrm{NF}_{3}: 209.0664$. Found 277.0675. Anal. $\left(\mathrm{C}_{8} \mathrm{H}_{10} \mathrm{O}_{2} \mathrm{NF}_{3} \cdot 0.25 \mathrm{H}_{2} \mathrm{O}\right) \mathrm{C}, \mathrm{H}, \mathrm{N}$. 
(1S,4R)-6-Dibromomethylene-2-(4-methoxybenzyl)-2-azabicyclo[2.2.1]

heptan-3-one (28)—Compound 16 (0.246 g, $1.0 \mathrm{mmol})$, carbon tetrabromide $(0.498 \mathrm{~g}, 1.5$ $\mathrm{mmol})$ and triphenylphosphine $(0.787 \mathrm{~g}, 3.0 \mathrm{mmol})$ were dissolved in anhydrous toluene $(10$ $\mathrm{mL}$ ), and the resulting light yellow suspension was stirred while refluxing under argon for 22 $\mathrm{h}$. The reaction mixture was then filtered, washed with benzene, and evaporated to give the crude product, which was purified via column chromatography on silica gel (hexanes: EtOAc 1:1) to give $28(377 \mathrm{mg}, 94 \%)$ as a light yellow oil. ${ }^{1} \mathrm{H}$ NMR $\left(500 \mathrm{MHz}, \mathrm{CDCl}_{3}\right) \delta 7.21(2 \mathrm{H}$, m), $6.85(2 \mathrm{H}, \mathrm{m}), 4.72(1 \mathrm{H}, \mathrm{d}, J=12.5 \mathrm{~Hz}), 4.20(1 \mathrm{H}, \mathrm{s}), 3.73-3.78(4 \mathrm{H}, \mathrm{m}), 3.03(1 \mathrm{H}, \mathrm{s}), 2.45$ $(1 \mathrm{H}, \mathrm{d}, J=16.5 \mathrm{~Hz}), 2.29(1 \mathrm{H}, \mathrm{d}, J=16.5 \mathrm{~Hz}), 2.02(1 \mathrm{H}, \mathrm{s}), 1.63(1 \mathrm{H}, \mathrm{s}) .{ }^{13} \mathrm{C} \mathrm{NMR}(126 \mathrm{MHz}$, $\left.\mathrm{CDCl}_{3}\right) \delta 177.41,159.15,145.83,129.45,128.51,114.04,81.58,64.27,55.28,45.66,44.49$, 40.84, 36.61. $\mathrm{m} / z(\mathrm{ESI}, \mathrm{MeOH}): 399.9(\mathrm{M})^{+}, 401.9(\mathrm{M}+2)^{+}, 404(\mathrm{M}+4)^{+}, 322.0(\mathrm{M}-\mathrm{Br})^{+}$, $293.9\left(\mathrm{M}-\mathrm{CH}_{3} \mathrm{OC}_{6} \mathrm{H}_{4}\right)^{+}$. HRMS calcd. For $\mathrm{C}_{15} \mathrm{H}_{15} \mathrm{O}_{2} \mathrm{NBr}_{2}$ : 398.9464. Found 398.9460.

(1S,4R)-2-(4-Methoxybenzyl)-6-(2,2,2-trifluoro-1-trifluoromethylethylidene)-2azabicyclo[2.2.1] heptan-3-one (29)—was synthesized from $\mathbf{2 8}$ in an 82\% yield using general procedure I $(50 \mathrm{~h}) .{ }^{1} \mathrm{H}$ NMR $\left(400 \mathrm{MHz}, \mathrm{CDCl}_{3}\right) \delta 7.15(2 \mathrm{H}, \mathrm{d}, J=8.8 \mathrm{~Hz}), 6.88(2 \mathrm{H}$, $\mathrm{d}, J=8.8 \mathrm{~Hz}), 4.82(1 \mathrm{H}, \mathrm{d}, J=15.2 \mathrm{~Hz}), 4.62(1 \mathrm{H}, \mathrm{s}), 3.81(3 \mathrm{H}, \mathrm{s}), 3.65(1 \mathrm{H}, \mathrm{d}, J=15.2 \mathrm{~Hz})$, $3.03(1 \mathrm{H}, \mathrm{s}), 2.82(1 \mathrm{H}, \mathrm{d}, J=18.4 \mathrm{~Hz}), 2.73(1 \mathrm{H}, \mathrm{d}, J=18.4 \mathrm{~Hz}), 2.12(1 \mathrm{H}, \mathrm{d}, J=10.4 \mathrm{~Hz})$, $1.63(1 \mathrm{H}, \mathrm{d}, J=10.4 \mathrm{~Hz}) .{ }^{19} \mathrm{~F} \mathrm{NMR}\left(376.49 \mathrm{MHz}, \mathrm{CDCl}_{3}\right) \delta-57.12--57.03(3 \mathrm{~F}, \mathrm{~m}),-59.97$ - $-59.91(3 \mathrm{~F}, \mathrm{~m}) . \mathrm{m} / z(\mathrm{EI}, \mathrm{DCM}): 379.1(\mathrm{M})^{+}, 380.1(\mathrm{M}+1)^{+}, 136.1(\mathrm{PMB}+\mathrm{NH})^{+}, 121.0$ $(\mathrm{PMB})^{+}$. HRMS calcd. For $\mathrm{C}_{16} \mathrm{H}_{16} \mathrm{O}_{2} \mathrm{NF}_{3}: 379.1001$. Found 379.1003 .

(1S,4R)-6-(2,2,2-Trifluoro-1-trifluoromethylethylidene)-2-azabicyclo[2.2.1] heptan-3-one (30)—was synthesized from 29 in a $56 \%$ yield using general procedure II. ${ }^{1} \mathrm{H}$ NMR $\left(400 \mathrm{MHz}, \mathrm{CDCl}_{3}\right) \delta 5.62(1 \mathrm{H}, \mathrm{s}), 4.78(1 \mathrm{H}, \mathrm{s}), 2.96(1 \mathrm{H}, \mathrm{s}), 2.83(1 \mathrm{H}, \mathrm{s}), 2.74$ $(1 \mathrm{H}, \mathrm{s}), 2.29(1 \mathrm{H}, \mathrm{s}), 1.71(1 \mathrm{H}, \mathrm{s}) .{ }^{19} \mathrm{~F}$ NMR $\left(376 \mathrm{MHz}, \mathrm{CDCl}_{3}\right) \delta-57.32(3 \mathrm{~F}, \mathrm{~s}),-60.25(3 \mathrm{~F}$, s). $\mathrm{m} / z(\mathrm{EI}, \mathrm{DCM}): 260.1(\mathrm{M}+1)^{+}, 259.1(\mathrm{M})^{+}, 189.1\left(\mathrm{M}-\mathrm{CF}_{3}\right)^{+}$. HRMS calcd. for $\mathrm{C}_{9} \mathrm{H}_{7} \mathrm{ONF}_{6}: 259.0426$. Found 259.0434.

(1S,3S)-3-Amino-4-(2,2,2-trifluoro-1-trifluoromethylethylidene)cyclopentane carboxylic acid (10)—was synthesized from 30 in a 77\% yield as a white solid using general procedure III; mp 198.0-199.5 ${ }^{\circ} \mathrm{C} ;{ }^{1} \mathrm{H}$ NMR $\left(\mathrm{D}_{2} \mathrm{O}, 400.169 \mathrm{MHz}\right) \delta 4.92(1 \mathrm{H}, \mathrm{s}), 3.29-3.34$ $(1 \mathrm{H}, \mathrm{m}), 3.16-3.20(2 \mathrm{H}, \mathrm{m}), 2.57-2.65(1 \mathrm{H}, \mathrm{m}), 2.20-2.27(1 \mathrm{H}, \mathrm{m}) .{ }^{19} \mathrm{~F}$ NMR $\left(\mathrm{D}_{2} \mathrm{O}, 376.493\right.$ MHz) $\delta-59.97(3 \mathrm{~F}, \mathrm{q}, J=9.0 \mathrm{~Hz}),-60.47(3 \mathrm{~F}, \mathrm{q}, J=9.0 \mathrm{~Hz}) .{ }^{13} \mathrm{C}$ NMR $\left(\mathrm{D}_{2} \mathrm{O}, 100.749 \mathrm{MHz}\right)$ $\delta 178.08,158.14,122.40,119.16-119.67(\mathrm{~m}), 52.56\left(\mathrm{~d}, J_{F C}=2.3 \mathrm{~Hz}\right), 40.73,36.31\left(\mathrm{q}, J_{F C}=\right.$ $3.8 \mathrm{~Hz}), 33.68 . \mathrm{m} / \mathrm{z}(\mathrm{EI}, \mathrm{MeOH}): 278.1(\mathrm{M}+1)^{+}, 277.1(\mathrm{M})^{+}, 259.1\left(\mathrm{M}-\mathrm{H}_{2} \mathrm{O}\right)^{+}, 232.0(\mathrm{M}-$ $\left.\mathrm{CO}_{2} \mathrm{H}\right)^{+}$. HRMS calcd. For $\mathrm{C}_{9} \mathrm{H}_{9} \mathrm{O}_{2} \mathrm{NF}_{6}$ : 277.0538. Found 277.0545. Anal.

$\left(\mathrm{C}_{9} \mathrm{H}_{9} \mathrm{O}_{2} \mathrm{NF}_{6} \cdot \mathrm{H}_{2} \mathrm{O}\right) \mathrm{C}, \mathrm{H}, \mathrm{N}$.

\section{Enzyme and Assays}

GABA aminotransferase was isolated from pig brains by a known procedure. ${ }^{34}$ Succinic semialdehyde dehydrogenase (SSDH) was isolated from GABAse, a commercially available mixture of SSDH and GABA aminotransferase, by inactivation of the GABA aminotransferase with gabaculine as described previously. ${ }^{35}$ GABA activity assays were carried out using a modification of the coupled assay developed by Scott and Jakoby. ${ }^{36}$ The assay solution contains $11 \mathrm{mM}$ GABA, $5.3 \mathrm{mM} \alpha$-ketoglutarate, $1.1 \mathrm{mM} \mathrm{NADP+}$, and $5 \mathrm{mM} \beta$ mercaptoethanol in $100 \mathrm{mM}$ potassium pyrophosphate, $\mathrm{pH}$ 8.5, and excess SSDH. Using this assay, the change in absorbance at $340 \mathrm{~nm}$ indicates production of NADPH, which is directly proportional to the activity of GABA aminotransferase. 


\section{Time-Dependent Inactivation of GABA Aminotransferase}

Incubation solutions ( $200 \mu \mathrm{L})$ contained enzyme $(30 \mu \mathrm{L})$, potassium pyrophosphate buffer (volume dependent on volume of inhibitor, $50 \mathrm{mM}$, pH 8.5), $\alpha$-ketoglutarate $(20 \mu \mathrm{L}, 16 \mathrm{mM}$ in $50 \mathrm{mM}$ potassium pyrophosphate buffer, $\mathrm{pH} 8.5)$, 2-mercaptoethanol $(2.0 \mathrm{mM})$, and various volumes of the inhibitor solutions $\left(\mathbf{6}, \mathbf{8}\right.$ and $9,0.2 \mathrm{M}$ in doubly distilled $\left.\mathrm{H}_{2} \mathrm{O}\right)$. The concentration of inhibitors was calculated based on a total volume of $200 \mu \mathrm{L}$. At time intervals, aliquots ( 27 $\mu \mathrm{L})$ from the incubation solution were added to the assay solution $(568 \mu \mathrm{L})$ with excess succinic semialdehyde dehydrogenase (SSDH). Rates were measured spectrophotometrically at 340 $\mathrm{nm}$, and the logarithm of the remaining activity (percentage) was plotted against time for each concentration to determine the half-time. Then a secondary plot of half-time versus the reciprocal of the inhibitor concentration was obtained to determine the $k_{\text {inact }}$ and $K_{\mathrm{I}}$ values.

\section{Exhaustive Dialysis of 6, 8 and 9 Inactivated GABA-AT with Potassium Pyrophosphate Buffer}

Incubation solutions $(200 \mu \mathrm{L})$ contained enzyme $(30 \mu \mathrm{L})$, potassium pyrophosphate buffer $(147$ $\mu \mathrm{L}, 50 \mathrm{mM}, \mathrm{pH} 8.5), \alpha$-ketoglutarate $(20 \mu \mathrm{L}, 16 \mathrm{mM}$ in $50 \mathrm{mM}$ potassium pyrophosphate buffer, $\mathrm{pH} 8.5)$, 2-mercaptoethanol $(2.0 \mathrm{mM})$, and the inhibitor solutions $(\mathbf{6}, 8$ and $9,3.0 \mu \mathrm{L}$, $0.2 \mathrm{M}$ in doubly distilled $\left.\mathrm{H}_{2} \mathrm{O}\right)$. A control solution $(200 \mu \mathrm{L})$ containing enzyme $(30 \mu \mathrm{L})$, potassium pyrophosphate buffer $(150 \mu \mathrm{L}, 50 \mathrm{mM}, \mathrm{pH} 8.5), \alpha$-ketoglutarate $(20 \mu \mathrm{L}, 16 \mathrm{mM}$ in $50 \mathrm{mM}$ potassium pyrophosphate buffer, $\mathrm{pH} 8.5), 2$-mercaptoethanol $(2.0 \mathrm{mM})$, and no inhibitor solution was also prepared. The incubation solution was allowed to stand at room temperature for about $1 \mathrm{~h}$ to ensure most of the enzyme was inactivated. The incubation solutions and the control solution were injected into a Slide-A-Lyzer ${ }^{\circledR}$ Dialysis Cassette (Extra Strength, $10000 \mathrm{MWCO}, 0.5-3.0 \mathrm{~mL}$ capacity), respectively, and stirred in a $1 \mathrm{~L}$ beaker containing a stirring bar and $800 \mathrm{~mL}$ of $50 \mathrm{mM}$ potassium pyrophosphate buffer $(\mathrm{pH} 8.5)$. The buffer was changed every $4 \mathrm{~h}$, at which point, an aliquot was taken out to assay.

\section{Substrate Protection against Inhibition of GABA-AT by Compounds 6, 8 and 9}

Incubation solutions $(200 \mu \mathrm{L})$ contained enzyme $(30 \mu \mathrm{L})$, potassium pyrophosphate buffer (volumes dependent on the volume of substrate, $50 \mathrm{mM}, \mathrm{pH} 8.5), \alpha$-ketoglutarate $(20 \mu \mathrm{L}, 16$ $\mathrm{mM}$ in $50 \mathrm{mM}$ potassium pyrophosphate buffer, $\mathrm{pH} 8.5), 2$-mercaptoethanol (2.0 $\mathrm{mM})$, inhibitor solutions $\left(2 \mu \mathrm{L}\right.$ or $0 \mu \mathrm{L}$ in control, 6,8 or 9 , respectively in doubly distilled $\mathrm{H}_{2} \mathrm{O}, 0.2$ M) and GABA solution [0 $\mu \mathrm{L}$ (control), $17.6 \mu \mathrm{L}$ and $35.2 \mu \mathrm{L}]$. The concentrations of GABA in the incubation solutions were $0 \mathrm{mM}$ (control), $3 \mathrm{mM}$, and $6 \mathrm{mM}$, respectively. At time intervals, aliquots $(27 \mu \mathrm{L})$ from the incubation solution were added to the assay solution (568 $\mu \mathrm{L}$ ) with excess succinic semialdehyde dehydrogenase (SSDH). Rates were measured spectrophotometrically at $340 \mathrm{~nm}$, and the remaining activity (percentage) was determined against the control and plotted versus time to determine the $\mathrm{t}_{1 / 2}$.

\section{Fluoride lon Released During Inhibition of GABA-AT by 5-10}

GABA-AT $(25 \mu \mathrm{L})$ was incubated for $3 \mathrm{~h}$ with each of the six compounds 5-10 $(0.8 \mathrm{mM})$ in $50 \mathrm{mM}$ potassium pyrophosphate buffer, $\mathrm{pH} 8.5$, containing $2.0 \mathrm{mM} \beta$-mercaptoethanol and $0.64 \mathrm{mM} \alpha$-ketoglutarate in a total volume of $250 \mu \mathrm{L}$ at $25^{\circ} \mathrm{C}$. A control containing no enzyme ( $25 \mu \mathrm{L}$ of buffer was added instead) was also run. The fluoride ion concentration $(200 \mu \mathrm{L})$ of each sample mixed with $1.00 \mathrm{~mL}$ of total ionic strength adjusting buffer (TISAB low level), $790 \mu \mathrm{L}$ of potassium pyrophosphate buffer, and $10 \mu \mathrm{L}$ of diluted standard fluoride solution $\left(2.38 \times 10^{-4} \mathrm{M}\right)$, was measured with a fluoride ion electrode.

\section{Fluoride lon Release During Inhibition of GABA-AT by 6 and 7 with Time}

GABA-AT $(120 \mu \mathrm{L})$ was incubated with 6 or $7(12 \mu \mathrm{L}, 0.2 \mathrm{M}$ in doubly distilled water) in 50 $\mathrm{mM}$ potassium pyrophosphate buffer, $\mathrm{pH} 8.5$, containing $2.0 \mathrm{mM} \beta$-mercaptoethanol and 0.64 $\mathrm{mM} \alpha$-ketoglutarate in a total volume of $1.2 \mathrm{~mL}$ at $25^{\circ} \mathrm{C}$. Another two samples containing no 
GABA-AT but serum albumin or just potassium pyrophosphate buffer (control) were also run. At time intervals, $200 \mu \mathrm{L}$ of each sample was removed and mixed with $1.00 \mathrm{~mL}$ of total ionic strength adjusting buffer (TISAB low level), $790 \mu \mathrm{L}$ of potassium pyrophosphate buffer, and $10 \mu \mathrm{L}$ of diluted standard fluoride solution $\left(2.38 \times 10^{-4} \mathrm{M}\right)$. The fluoride ion concentration was measured with a fluoride ion electrode.

\section{Supplementary Material}

Refer to Web version on PubMed Central for supplementary material.

\section{Acknowledgment}

The authors are grateful to the National Institutes of Health (GM66132) for financial support of this research.

\section{Abbreviations}

CAN, ceric ammonium nitrate

DBDMH, 1,3-dibromo-5,5-dimethylhydantoin

GABA, $\gamma$-aminobutyric acid

GABA-AT, $\gamma$-aminobutyric acid aminotransferase

GAD, L-glutamic acid decarboxylase

LiHMDS, lithium hexamethyldisilazide

MFSDA, methyl fluorosulfonyldifluoroacetate

PMBCl, $p$-methoxybenzyl chloride

SSA, succinic semialdehyde dehydrogenase

TBAF, tetrabutylammonium fluoride

TPAP, tetra-n-propylammonium perruthenate

\section{References}

1. McGeer, EG.; McGeer, PL.; Thompson, S. GABA and Glutamate Enzymes. In: Hertz, L.; Kvamme, E.; McGeer, EG.; Schousboe, A., editors. Glutamine, Glutamate, and GABA in the Central Nervous System. Liss; New York: 1983. p. 3-17.

2. Baxter CF, Roberts E. The $\gamma$-Aminobutyric Acid- $\alpha$-Ketoglutaric Acid Transaminase of Beef Brain. J. Biol. Chem 1958;233:1135-1139. [PubMed: 13598746]

3. Karlsson A, Fonnum F, Malthe-Sorrensen D, Storm-Mathisen J. Effect of the convulsive agent 3mercaptopropionic acid on the levels of GABA, other amino acids and glutamate decarboxylase in different regions of the rat brain. Biochem. Pharmacol 1974;23:3053-3061. [PubMed: 4154755]

4. Gale K. GABA in epilepsy: the pharmacologic basis. Epilepsia 1989;30(Suppl 3):S1-S11. [PubMed: 2548836]

5. Bakay RAE, Harris AB. Neurotransmitter, receptor and biochemical changes in mondey cortical epileptic foci. Brain Res 1981;206:387-404. [PubMed: 6111378]

6. Loyd, KG.; Munari, C.; Bossi, L.; Stoeffels, C.; Talairach, J.; Morselli, PL. Biochemical Evidence for the Alterations of GABA-Mediated Synaptic Transmission in Pathological Brain Tissue (Stereo EEG or Morphological Definition) from Epileptic Patients. In: Morselli, PL.; Loescher, W.; Loyd, KG., editors. Neurotransmission, Seizures, Epilepsy. Raven Press; New York: 1981. p. 325-338.

7. (a) Perry TL, Hansen S, Lesk D, Kloster M. Amino Acids in Plasma, Cerebrospinal Fluid, and Brain of Patients with Huntington's Chorea. Adv. Neurol 1972;1:609-618.McGeer, PL.; McGeer, EG. The GABA System and Function of the Basal Ganglia: Huntington's Disease. In: Roberts, E.; Chase, TN.; Tower, DB., editors. GABA in Nervous System Function. Raven Press; New York: 1976. p. 487-495.

8. (a) Butterworth J, Yates CM, Simpson J. Phosphate-activated glutaminase in relation to Huntington's disease and agonal state. J. Neurochem 1983;41:440-447. [PubMed: 6223989] (b) Spokes EGS. Brain temperature after death. J. Neurosci. Meth 1980;2:105-106. (c) Wu JY, Bird ED, Chen MS, Huang WM. Abnormalities of neurotransmitter enzymes in Huntington's chorea. Neurochem. Res 
1979;4:575-586. [PubMed: 40150] (d) Iversen LL, Bird ED, Mackay AVP, Rayner CN. Analysis of glutamate decarboxylase in post-mortem brain tissue in Huntington's chorea. J. Psychiat. Res 1974;11:255-256. [PubMed: 4282387]

9. Nishino N, Fujiwara H, Noguchi-Kuno S-A, Tanaka C. GABA receptor but not muscarinic receptor density was decreased in the brain of patients with Parkinson's disease. Jpn. J. Pharmacol 1988;48:331339. [PubMed: 2851679]

10. (a) Maker HS, Weiss C, Weissbarth S, Silides DJ, Whetsell W. Regional activities of metabolic enzymes and glutamate decarboxylase in human brain. Ann. Neurol 1981;10:377-383. [PubMed: 7316490] (b) Rinne UK, Laaksonen H, Riekkinen P, Sonninen V. Brain glutamic acid decarboxylase activity in Parkinson's disease. Eur. Neurol 1974;12:13-19. [PubMed: 4412241] (c) McGeer PL, McGeer EG, Wada JA, Jung E. Effects of globus pallidus lesions and Parkinson's disease on brain glutamic acid decarboxylase. Brain Res 1971;32:425-431. [PubMed: 4944072]

11. (a) Aoyagi T, Wada T, Nagai M, Kojima F, Harada S, Takeuchi T, Takahashi H, Hirokawa K, Tsumita T. Increased $\gamma$-aminobutyrate aminotransferase activity in brain of patients with Alzheimer's disease. Chem. Pharm. Bull 1990;38:1748-1749. [PubMed: 2208389] (b) Davies P. Neurotransmitter-related enzymes in senile dementia of the Alzheimer type. Brain Res 1979;171:319-327. [PubMed: 37989] (c) Perry EK, Gibson PH, Blessed G, Perry RH, Tomlinson BE. Neurotransmitter enzyme abnormalities in senile dementia. Choline acetyltransferase and glutamic acid decarboxylase activities in necripsy brain tissue. J. Neurol. Sci 1977;34:247-265. [PubMed: 144789] (d) Bowen DM, White P, Flack RHA, Smith CB, Davison NA. Brain-decarboxylase activities as indices of pathological change in senile dementia. Lancet 1974;1:1247-1249. [PubMed: 4134959] (e) Kodama K, Kaitani H, Nanba M, Kondo T, Mikame F, Yoshida H, Sato K, Yanaihara N. Neurotransmitter analogs in body fluids of patients with dementia. Shinkei Kagaku 1981;20:496.

12. Gunne LM, Haeggstroem JE, Sjoequist B. Association with persistent neurolepticinduced dyskinesia of regional changes in brain GABA synthesis. Nature (London) 1984;309:347-349. [PubMed: 6727989]

13. (a) Johnston GAR, Curtis DR, Beart PM, Game CJA, McColloch RM, Twichin B. Cis- and trans-4aminocrotonic acid as GABA analogues of restricted conformation. J. Neurochem 1975;24:157-160. [PubMed: 234147] (b) Schon F, Kelly JS. The Characterisation of [3H]GABA Uptake into the Satellite Glial Cells of Rat Sensory Ganglia. Brain Res 1974;66:289-300. (c) Johnston GAR, Stephanson AL, Twichin B. Piperazic acid and related compounds as inhibitors of GABA uptake in rat brain slices. J. Pharm. Pharmacol 1977;29:240-241. [PubMed: 17676] (d) Brehm L, Hjeds H, Krogsgarrd-Larsen P. The structure of muscimol, a GABA analogue of restricted conformation. Acta Chem. Scand 1972;26:1298-1299. [PubMed: 5079744] (e) Krogsgaard-Larsen P, Johnston GAR, Lodge D, Curtis DR. A new class of GABA agonist. Nature (London) 1977;268:53-55. [PubMed: 196200] (f) Beart PM, Curtis DR, Johnston GAR. 4-aminotetrolic acid: new conformationalrestricted analogue of $\gamma$-aminobutyric acid. Nature (New Biol.) 1971;234:80-81. [PubMed: 5288736] (g) Beart PM, Johnston GAR. GABA [ $\gamma$-aminobutyric acid] uptake in rat brain slices. Inhibition by GABA analogs and by various drugs. Aust. J. Chem 1972;25:1359-1361.

14. Silverman, RB. Mechanism-Based Enzyme Inactivation: Chemistry and Enzymology. I and II. CRC Press; Boca Raton, FL: 1988. (b) Silverman RB. Mechanism-Based Enzyme Inactivators. Methods Enzymol 1995;249:240-283. [PubMed: 7791614]

15. Nanavati SM, Silverman RB. Design of potential anticonvulsant agents: mechanistic classification of GABA aminotransferase inactivators. J. Med. Chem 1989;32:2413-2421. [PubMed: 2681782]

16. Lippert B, Metcalf BW, Jung MJ, Casara P. 4-amino-hex-5-enoic acid, a selective catalytic inhibitor of 4-aminobutyric-acid aminotransferase in mammalian brain. Eur. J. Biochem 1977;74:441-445. [PubMed: 856582]

17. Loscher W. Comparative assay of anticonvulsant and toxic potencies of sixteen GABAmimetic drugs. Neuropharmacol 1982;21:803-810.

18. (a) Tassinari CA, Michelucci R, Ambrosetto G, Salvi F. Double-blind study of vigabatrin in the treatment of drug-resistant epilepsy. Arch. Neurol 1987;44:907-910. [PubMed: 2887152] (b) Browne TR, Mattson RJ, Penry JK, Smith DB, Treiman DM, Wilder BJ, Ben-Menachem E, Miketta RM, Sherry KM, Szabo GK. A multicentre study of vigabatrin for drug-resistant epilepsy. Br. J. Clin. Pharmacol 1989;27:95S-100S. [PubMed: 2667606] (c) Sivenius MR, Ylinen A, Murros K, Matilainen R, Riekkinen P. Double-blind dose reduction study of vigabatrin in complex partial epilepsy. Epilepsia 1987;28:688-692. [PubMed: 3319536] 
19. Dewey SL, Morgan AE, Ashby CR Jr. Horan B, Kushner SA, Logan J, Volkow ND, Fowler JS, Gardner EL, Brodie JD. A novel strategy for the treatment of cocaine addiction. Synapse 1998;30:119-129. [PubMed: 9723781]

20. Dewey SL, Brodie JD, Gerasimov M, Horan B, Gardner EL, Ashby CR Jr. A pharmacologic strategy for the treatment of nicotine addiction. Synapse 1999;31:76-86. [PubMed: 10025686]

21. Gerasimov MR, Ashby CR, Gardner EL, Mills MJ, Brodie JD, Dewey SL. Gamma-vinyl GABA inhibits methamphetamine, heroin, or ethanol-induced increases in nucleus accumbens dopamine. Synapse 1999;34:11-19. [PubMed: 10459167]

22. Kushner SA, Dewey SL, Kornetsky C. The irreversible $\gamma$-aminobutyric acid (GABA) transaminase inhibitor $\gamma$-vinyl-GABA blocks cocaine self-administration in rats. J. Pharmacol. Exp. Ther 1999;290:797-802. [PubMed: 10411594]

23. (a) Nanavati SM, Silverman RB. Mechanism of Inactivation of $\gamma$-Aminobutyric Acid Aminotransferase by the Antiepilepy Drug $\gamma$-Vinyl GABA (Vigabatrin). J. Am. Chem. Soc 1991;113:9341-9349. (b) Allan RD, Twitchin B. Synthesis of Analogues of GABA. IV Three Unsaturated Derivatives of 2-Aminocyclopentane-1-carboxylic Acid. Aust. J. Chem 1980;33:599604. (c) Allan RD, Fong J. Synthesis of Analogues of GABA. XV Preparation and Resolution of Some Potent Cyclopentene and Cyclopentane Derivatives. Aust. J. Chem 1986;39:855-864. (d) Galeazzi R, Mobbili G, Orena M. Modeling and Synthesis of Conformationally Restricted Amino Acids. Current Organic Chemistry 2004;8:1799-1929.

24. Qiu J, Pingsterhaus J, Silverman RB. Inhibition and Substrate Activity of Conformationally Rigid Vigabatrin Analogues with $\gamma$-Aminobutyric Acid Aminotransferase. J. Med. Chem 1999;42:47254728. [PubMed: 10579835]

25. Pan Y, Qiu J, Silverman RB. Design, Synthesis, and Biological Activity of a Difluoro- Substituted, conformationally Rigid Vigabatrin Analogue as a Potent $\gamma$-Aminobutyric Acid Aminotransferase Inhibitor. J. Med. Chem 2003;46:5292-5293. [PubMed: 14640537]

26. (a) Park BK, Kitteringham NR, O'Neill PM. Metabolism of fluorine-containing drugs. Ann. Rev. Pharmacol. Toxicol 2001;41:443-470. [PubMed: 11264465] (b) Ismail FMD. Important fluorinated drugs in experimental and clinical use. J. Fluorine Chem 2002;118:27-33.

27. Iseki, K. Asymmetric Fluoroalkylation. In: Soloshonok, VA., editor. Enantiocontrolled Synthesis of Fluoro-organic Compounds. John Wiley \& Sons; New York: 2001. p. 33-62.

28. Pongdee R, Liu H-W. Elucidation of Enzyme Mechanisms Using Fluorinated Substrate Analogues. Bioorganic Chemistry 2004;32:393-437. [PubMed: 15381404]For a recent review, see:

29. Qiu J, Silverman RB. A New Class of Conformationally Rigid Analogues of 4-Amino-5halopentanoic Acids, Potent Inactivators of $\gamma$-Aminobutyric Acid Aminotransferase. J. Med. Chem 2000;43:706-720. [PubMed: 10691696]

30. Krishnamurti R, Bellew DR, Prakash GKS. Preparation of Trifluoromethyl and Other Perfluoroalkyl Compounds with (Perfluoroalkyl)trimethylsilanes. J. Org. Chem 1991;56:984-989.

31. Chen, Q.; Wu, S. Methyl (fluorosulfonyl)difluoroacetate; a new trifluoromethylating agent; J. Chem. Soc. Chem. Commun. 1989. p. 705-706.

32. Natuzzi D, Daddabbo L, Stipani V, Cappello AR, Miniero DV, Capobianco L, Stipani I. Inactivation of the Reconstituted Oxoglutarate Carrier from Bovine Heart Mitochondria by Pyridoxal 5'Phosphate. J. Bioenergetics \& Biomembranes 1999;31:535-541.

33. Yamazaki T, Hiraoka S, Kitazume T. Ready Carbon-Carbon Bond Formation of 2- (Trifluoromethy1) acrylate via Michael Addition Reactions. J. Org. Chem 1994;59:5100-5103.

34. Koo YK, Nandi D, Silverman RB. Multiple Active Enzyme Species of $\gamma$-Aminobutyric Acid Aminotransferase are not Isozymes, but are Proteolytic Fragments. Arch. Biochem. Biophys 2000;374:248-254. [PubMed: 10666304]

35. Jeffery D, Weitzman PDJ, Lunt GG. An improved assay for 4-aminobutyrate:2- oxoglutarate aminotransferase. Insect Biochem 1988;28:347-349.

36. Scott EM, Jakoby WB. Soluble $\gamma$-Aminobutyric-Glutamic Transaminase from Pseudomonas fluorescens. J. Biol. Chem 1958;234:932-936. [PubMed: 13654294] 

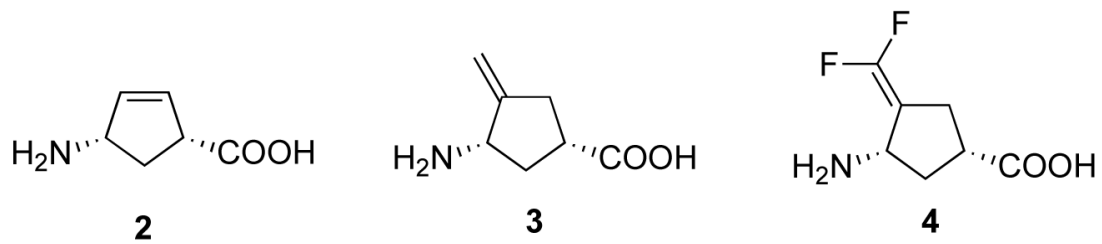

Figure 1.

Vigabatrin (1) and conformationally-restricted analogues 
<smiles>N[C@@H]1C[C@H](C(=O)O)C=C1F</smiles>

5

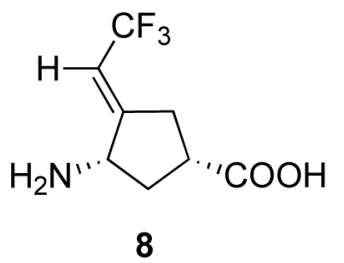

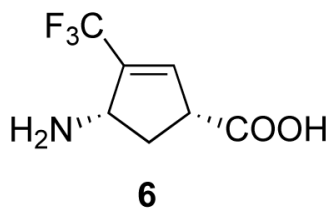

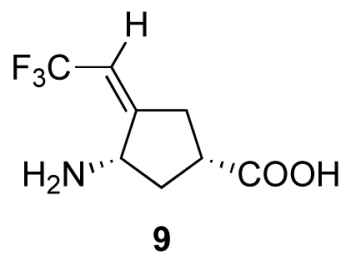

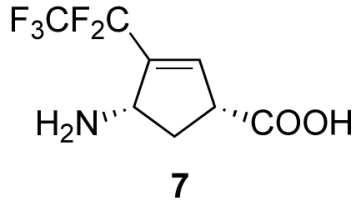

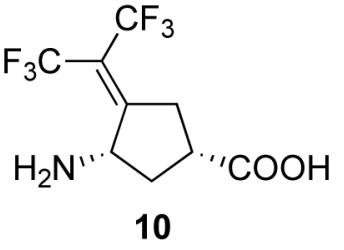

Figure 2.

New fluorinated conformationally-restricted potential inhibitors and inactivators of GABAAT 


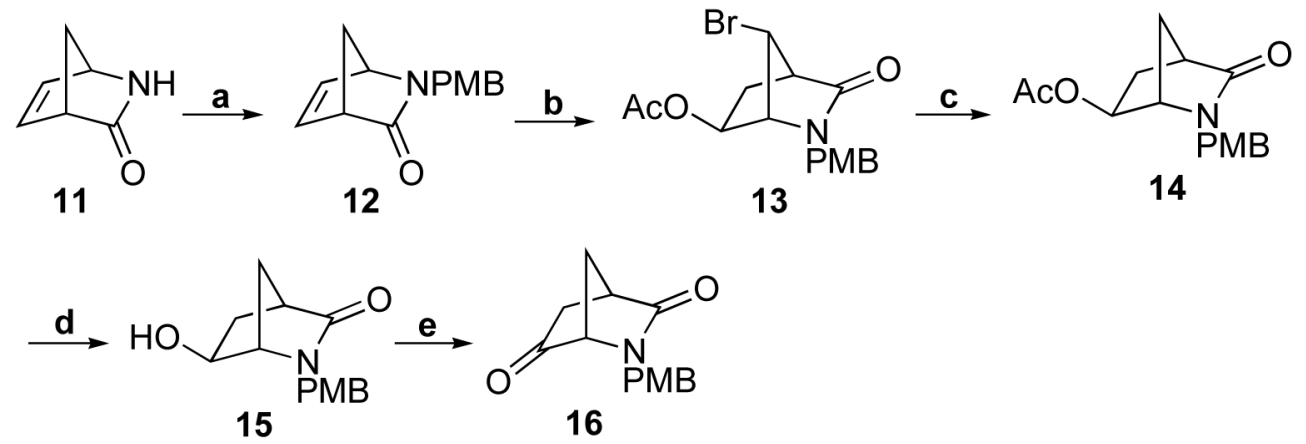

Scheme 1.

Reagents and conditions: a, $\mathrm{PMBCl}, \mathrm{NaH}, \mathrm{Bu}_{4} \mathrm{NI}, \mathrm{DMF}, 0{ }^{\circ} \mathrm{C}$ - r.t., $2 \mathrm{~h}, 83 \%$; b, DBDMH, $\mathrm{HOAc}$, r.t., 20h, $97 \%$; c, $\mathrm{Bu}_{3} \mathrm{SnH}$, $\mathrm{AIBN}, \mathrm{PhH}$, reflux, $12 \mathrm{~h}, 95 \%$; d, $\mathrm{K}_{2} \mathrm{CO}_{3}, \mathrm{MeOH}, \mathrm{H}_{2} \mathrm{O}$, r.t., 2h, 87\%; e, NMO, TPAP, DCM, r.t., 24h, 70\%. 


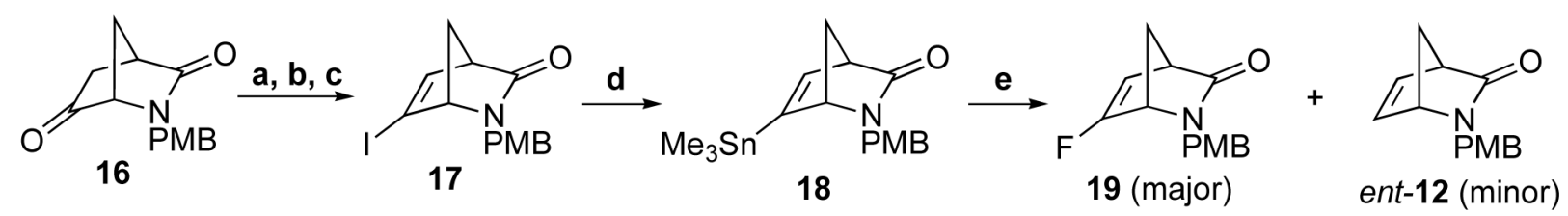

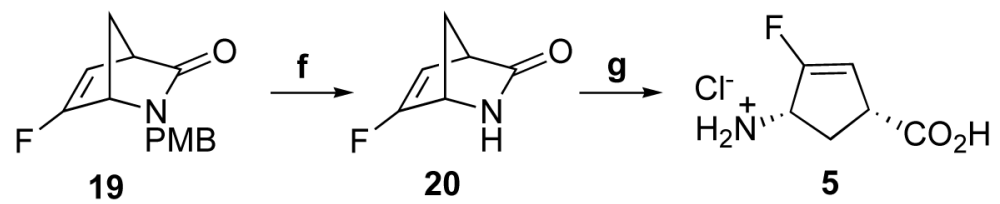

Scheme 2.

Reagents and conditions: $\mathbf{a}, \mathrm{NH}_{2} \mathrm{NH}_{2} \cdot \mathrm{H}_{2} \mathrm{O}, \mathrm{Et}_{3} \mathrm{~N}$, EtOH, reflux, $1 \mathrm{~h} ; \mathbf{b}, \mathrm{I}_{2}, \mathrm{Et}_{3} \mathrm{~N}$, benzene, r.t., $2 \mathrm{~h}$; c, t-BuOK, ether, r.t., $20 \mathrm{~h}, 60 \%$ in three steps; $\mathbf{d}, \mathrm{Me}_{3} \mathrm{SnSnMe}_{3}, \mathrm{Pd}\left(\mathrm{PPh}_{3}\right)_{4}, \mathrm{PhMe}$, reflux, 30 min, 49\%; e, $\mathrm{XeF}_{2}$, AgOTf, 2,6-bis(tert-butyl)-4-methylpyridine, DCM, r.t., 8 min, 30\%; f, $\mathrm{CAN}, \mathrm{CH}_{3} \mathrm{CN}, \mathrm{H}_{2} \mathrm{O}$, r.t., $2 \mathrm{~h}, 55 \% ; \mathbf{g}, 4 \mathrm{~N} \mathrm{HCl}$ (aq.), $70{ }^{\circ} \mathrm{C}, 0.5-1 \mathrm{~h}, 64 \%$ 

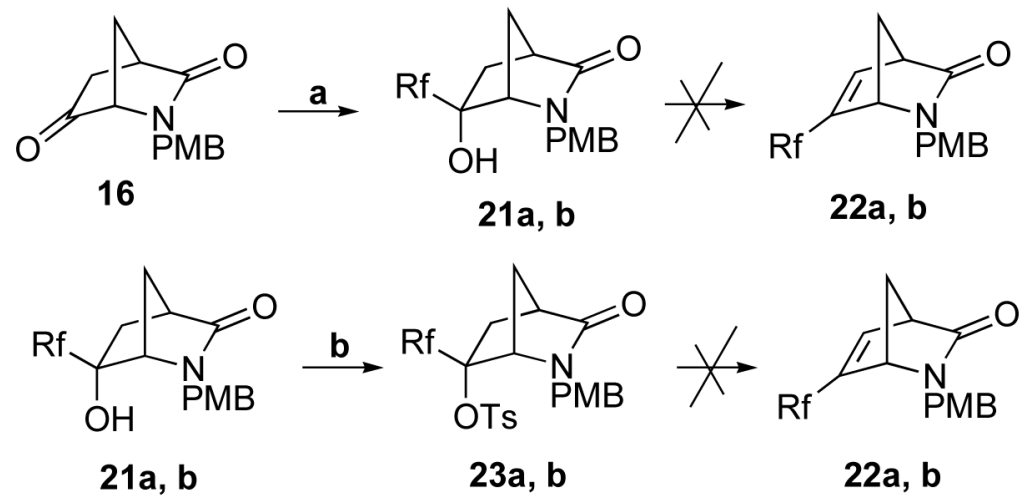

a, $\mathrm{Rf}=\mathrm{CF}_{3} ; \mathbf{b}, \mathrm{Rf}=\mathrm{CF}_{3} \mathrm{CF}_{2}$.

Scheme 3.

Reagents and conditions: a, TMSRf, TBAF (cat.), THF, r.t., 1 h, 95\%; b, TsCl, NaH, ether, 0 ${ }^{\circ} \mathrm{C}, 16$ h, $79 \%$. 

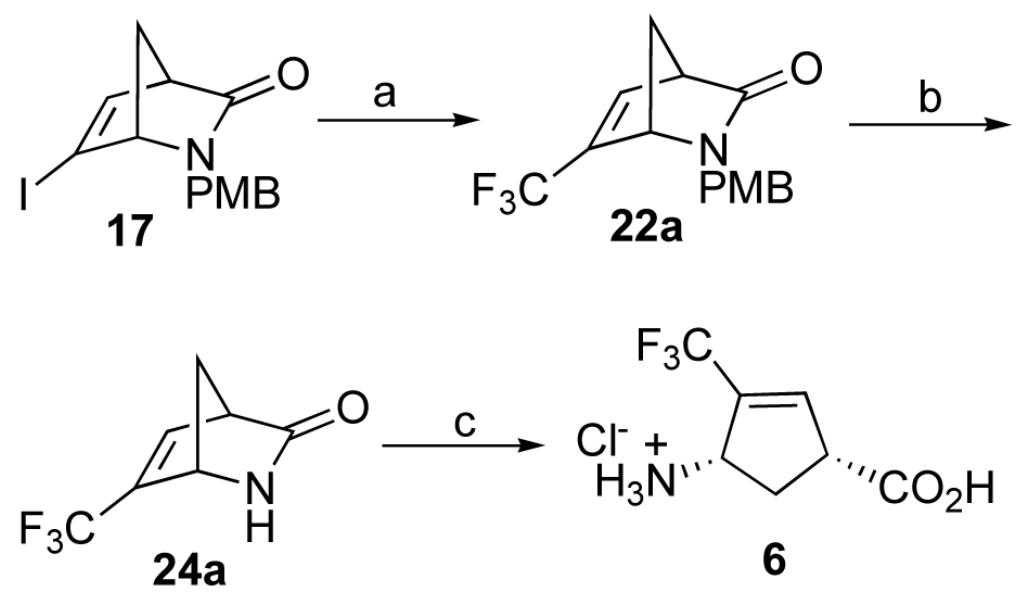

Scheme 4.

Reagents and conditions: a, MFSDA, CuI, DMF, HMPA, 20 h, 75\%; b, CAN, MeCN/H ${ }_{2} \mathrm{O}$, r.t., 3 h, $61 \%$; c, $4 \mathrm{~N} \mathrm{HCl}$ (aq.), $70{ }^{\circ} \mathrm{C}, 0.5-1$ h, $85 \%$. 


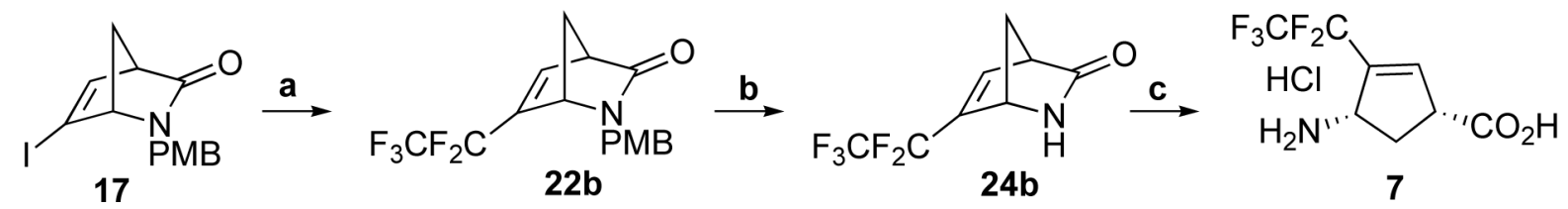

Scheme 5 .

Reagents and conditions: $\mathbf{a}, \mathrm{CF}_{3} \mathrm{CF}_{2} \mathrm{SiMe}_{3} / \mathrm{KF} / \mathrm{CuI}, \mathrm{NMO} / \mathrm{DMF}(1 / 1), 75^{\circ} \mathrm{C}, 24 \mathrm{~h}, 57 \%$; b, $\mathrm{CAN}, \mathrm{CH}_{3} \mathrm{CN}, \mathrm{H}_{2} \mathrm{O}$, r.t., 2 h, $76 \%$; c, $4 \mathrm{~N} \mathrm{HCl}$ (aq.), $70{ }^{\circ} \mathrm{C}, 0.5-1$ h, $82 \%$. 

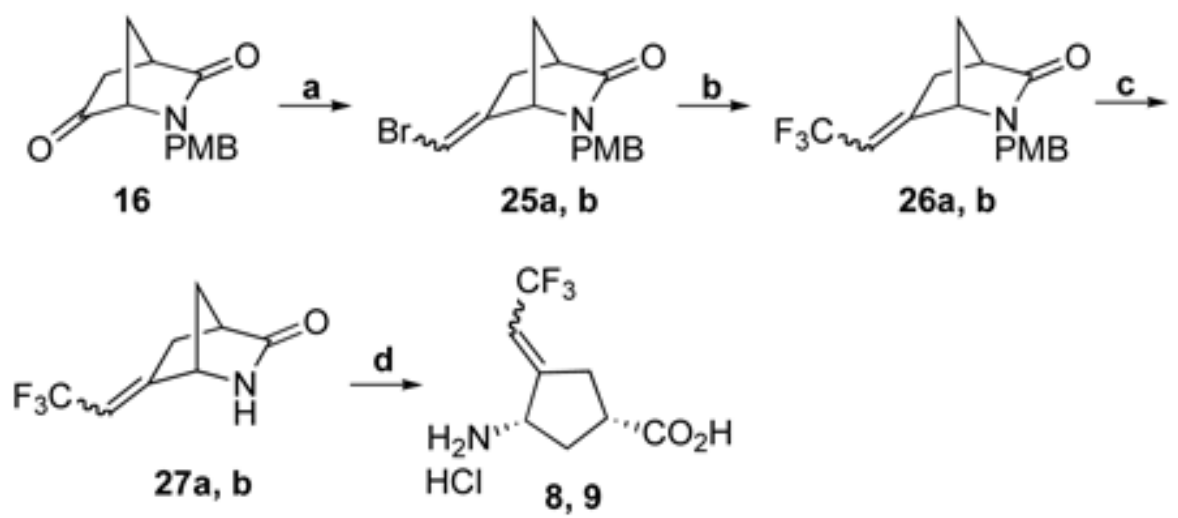

Scheme 6.

Reagents and conditions: a, $\mathrm{BrCH}_{2} \mathrm{PPh}_{3}$. Br, tert-BuOK, THF, -78 C, 20 h, 72\% E/Z; b, MFSDA, CuI, DMF, HMPA, $75^{\circ} \mathrm{C}, 20$ h, 95\%; c, CAN, $\mathrm{CH}_{3} \mathrm{CN}, \mathrm{H}_{2} \mathrm{O}$, r.t., 2 h, 76\%; d, 4N $\mathrm{HCl}$ (aq.), $70^{\circ} \mathrm{C}, 10-12 \mathrm{~h}, 79 \%$. 


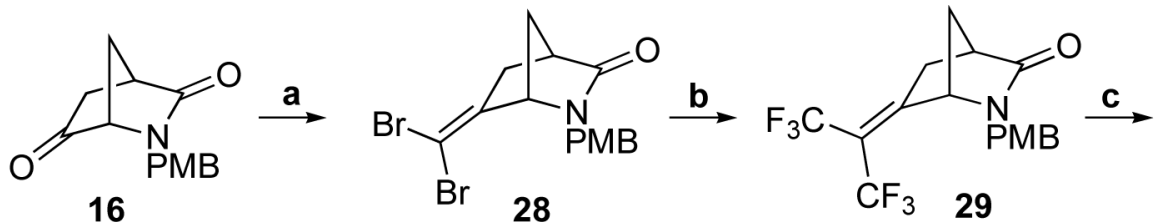<smiles>O=C1NC2CC1CC2=C(C(F)(F)F)C(F)(F)F</smiles><smiles>N[C@@H]1C[C@H](C(=O)O)CC1=C(C(F)(F)F)C(F)(F)F</smiles>

Scheme 7.

Reagents and conditions: a, $\mathrm{CBr}_{4}, \mathrm{PPh}_{3}$, toluene, reflux, $22 \mathrm{~h}, 86 \%$; b, MFSDA, CuI DMF, HMPA, $75^{\circ} \mathrm{C}, 50$ h, $82 \%$; c, $\mathrm{CAN}, \mathrm{CH}_{3} \mathrm{CN}, \mathrm{H}_{2} \mathrm{O}$, r.t., 1 h, $56 \%$; d, $4 \mathrm{~N} \mathrm{HCl}$ (aq.), $70{ }^{\circ} \mathrm{C}, 10-12$ h, $77 \%$. 


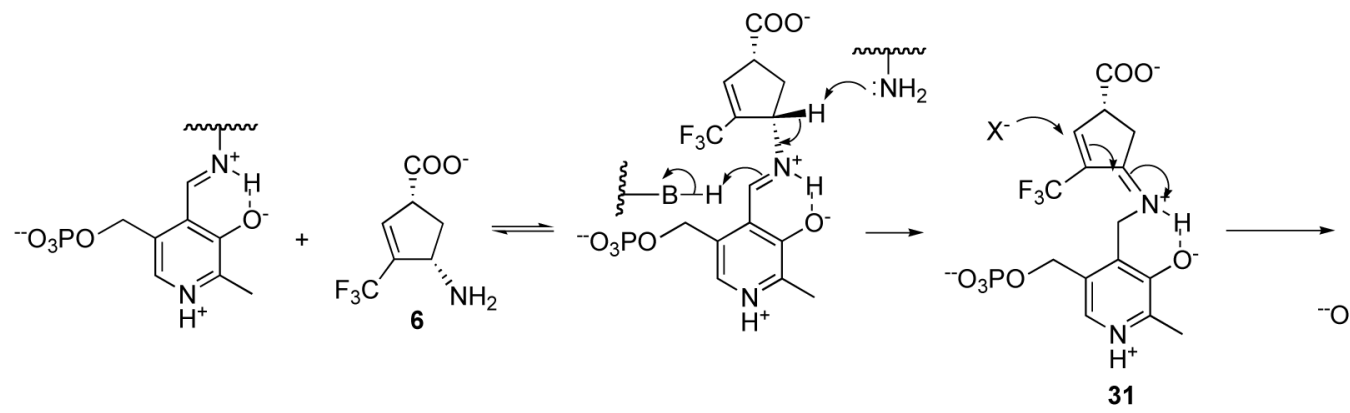

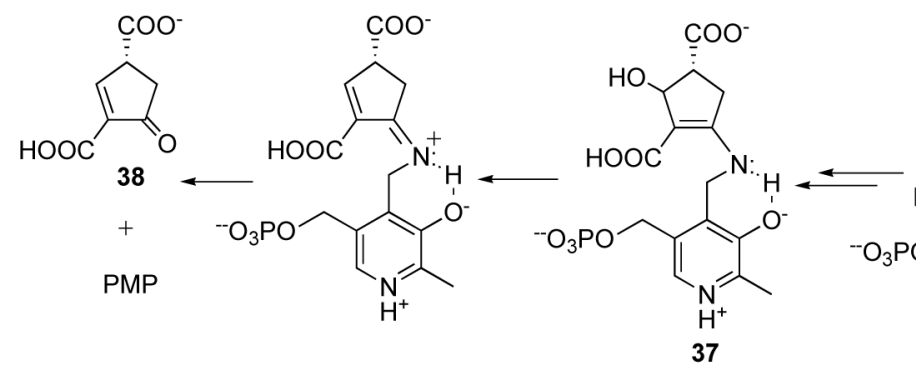<smiles>[Y]C(C)=O</smiles>
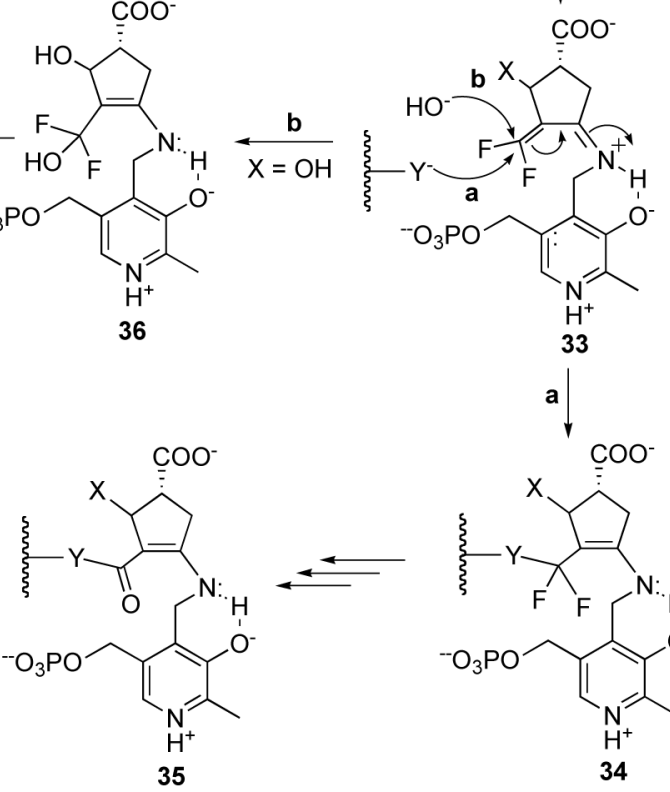

a

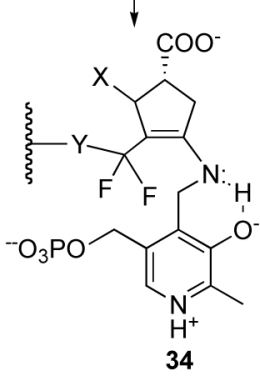

Scheme 8. 


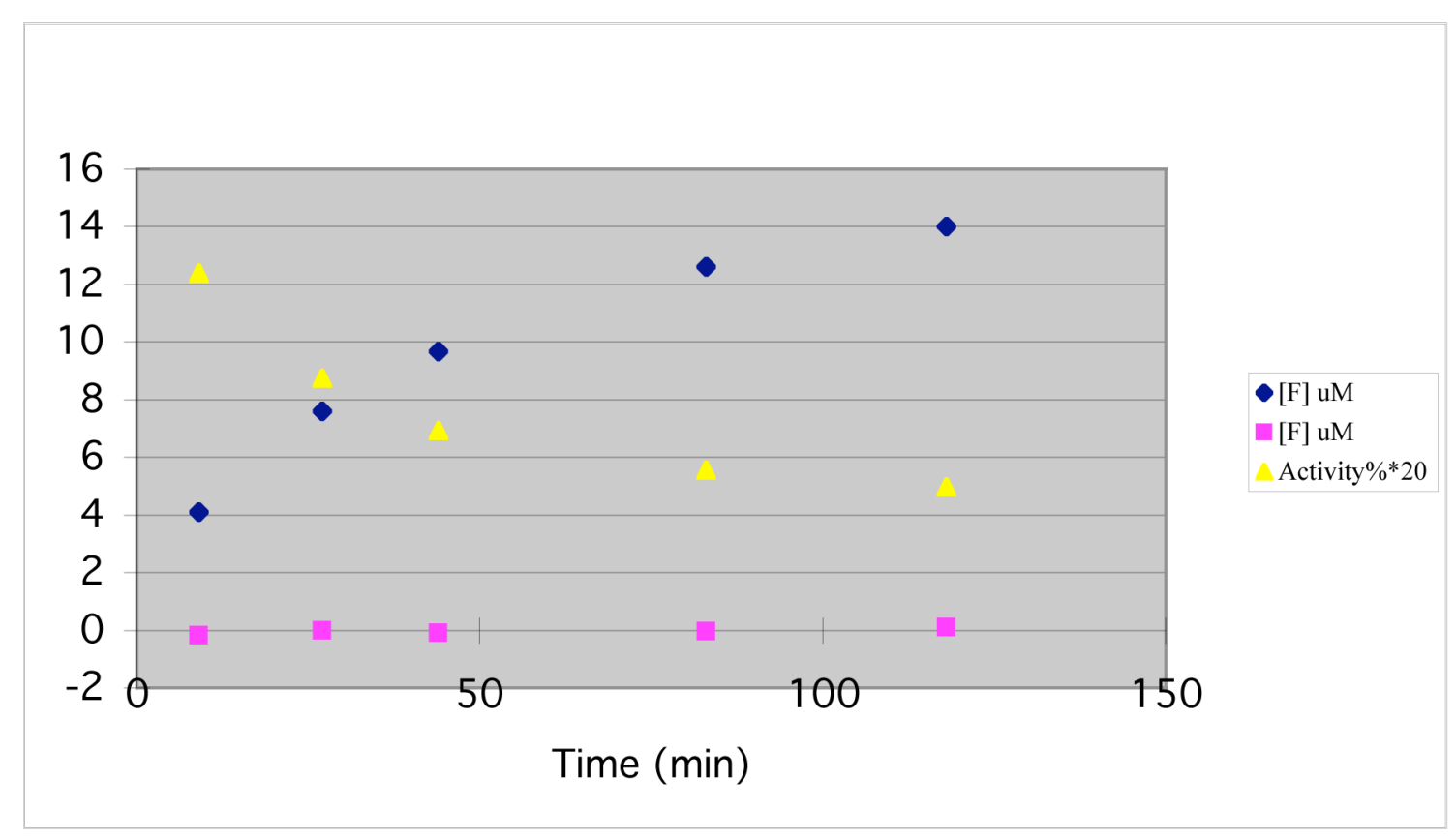

Figure 3.

Enzyme activity and fluoride ion release during inactivation of GABA-AT with $6(2 \mathrm{mM})$ as a function of time. Fluoride ion concentration when GABA-AT was incubated with 6 (diamonds); fluoride ion concentration when human albumin was incubated with 6 (squares); remaining relative enzyme activity as compared to control when GABA-AT was incubated with 6 (triangles). 


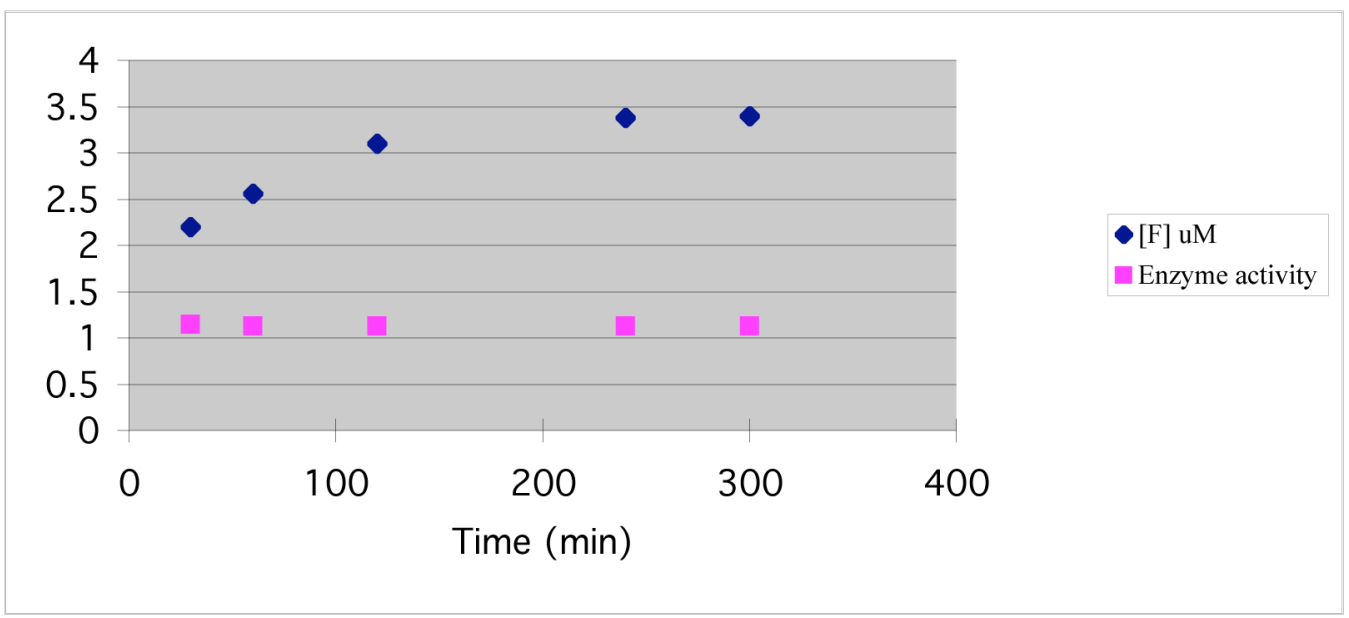

Figure 4.

Enzyme activity and fluoride ion release during inactivation of GABA-AT with 7 (2 mM) as a function of time. Fluoride ion concentration when GABA-AT was incubated with 7 (diamonds); remaining relative enzyme activity as compared to control when GABA-AT was incubated with 7 (squares). 
Table 1

Kinetic constants for 5-10

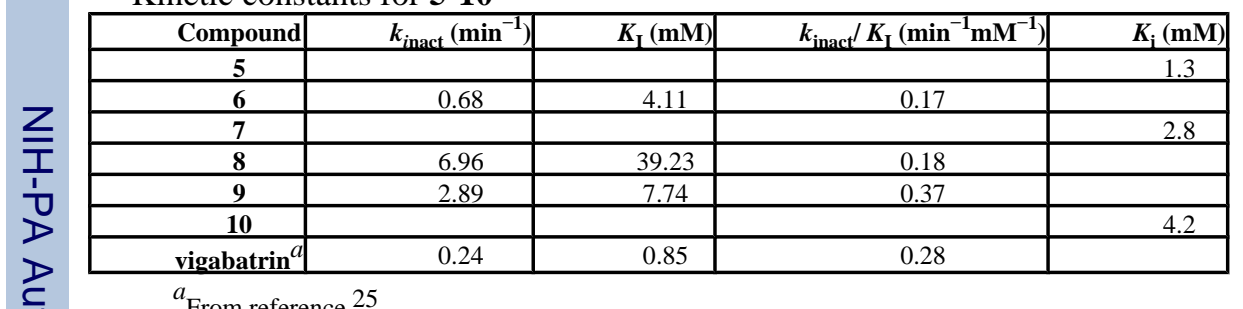

$a_{\text {From reference }} 25$ 